NBER WORKING PAPER SERIES

\title{
DO RELIGIOUS PROSCRIPTIONS MATTER? EVIDENCE FROM A THEORY-BASED TEST
}

Daniel M. Hungerman

Working Paper 17375

http://www.nber.org/papers/w17375

\author{
NATIONAL BUREAU OF ECONOMIC RESEARCH \\ 1050 Massachusetts Avenue \\ Cambridge, MA 02138 \\ August 2011
}

Thanks to Earl Grinols and David Mustard for providing data, and to audiences at Princeton, Ohio State, Florida State, Harvard, SUNY-Albany, the University of California San Diego, the University of California Merced, the Federal Reserve Bank of Chicago, the University of Illinois-Chicago, the ASREC Association, and Notre Dame. The views expressed herein are those of the author and do not necessarily reflect the views of the National Bureau of Economic Research.

NBER working papers are circulated for discussion and comment purposes. They have not been peerreviewed or been subject to the review by the NBER Board of Directors that accompanies official NBER publications.

(C) 2011 by Daniel M. Hungerman. All rights reserved. Short sections of text, not to exceed two paragraphs, may be quoted without explicit permission provided that full credit, including $\odot$ notice, is given to the source. 
Do Religious Proscriptions Matter? Evidence from a Theory-Based Test

Daniel M. Hungerman

NBER Working Paper No. 17375

August 2011

JEL No. H23,I1,Z12

\begin{abstract}
$\underline{\text { ABSTRACT }}$
A large literature shows that religious participation is associated with a wide range of behaviors and outcomes, but what drives this association is unclear. On the one hand, this association may stem from correlations in preferences, where those with tastes for religion coincidentally have particular tastes for other behaviors as well. Alternately, religious participation may directly affect behavior; for example many religious organizations impose rules and proscriptions on their members and these rules may affect members' decisions. Using the canonical economic model of religiosity, I develop an empirical test to investigate the importance of religious proscriptions on behavior. Several empirical applications of this test are conducted; the results indicate a strong role for religious proscriptions in determining behavior. The test developed here does not require an instrumental variable for religion and could be applied to the study of criminal gangs, terrorist organizations, fraternities, communes, political groups, and other "social clubs."
\end{abstract}

Daniel M. Hungerman

Department of Economics

University of Notre Dame

439 Flanner Hall

Notre Dame, IN 46556-5602

and NBER

dhungerm@nd.edu 


\section{Introduction}

Religious individuals often have different outcomes than other individuals. Highly religious individuals are less likely to drink heavily or use illegal drugs, are less likely to engage in risky sexual behavior, are less likely to engage in criminal activities and have lower recidivism upon leaving the criminal justice system, are more likely to be married, report better health outcomes along a vast number of dimensions, live longer, have higher levels of civic participation, and are more likely to make charitable contributions. These differences have been well established by hundreds of studies across the social sciences. Moreover, these differences are large in magnitude; religiosity is one of the strongest known predictors for outcomes such as charitable giving, civic participation, and risky behavior. ${ }^{1}$

A crucial question unanswered by prior research is whether the relationship between religion and other outcomes is causal. On the one hand, if individuals with a preference for religion are also individuals with preferences against things like binge drinking, these individuals would be observed undertaking lower levels of "sinful" activities than others; but this behavior could reflect a correlation of preferences rather than any direct impact of religiosity. On the other hand, religious participation may directly affect outcomes. For example, many religious organizations, like many voluntary secular organizations, actively proscribe activities and behaviors and such rules and restrictions may affect how members behave. Indeed, researchers interested in religious groups and other social clubs have often questioned why individuals participating in a voluntary activity would willingly submit to rules and restrictions that limit members’ behavior.

Typically, an economist might explore a direct effect of religion on behavior by identifying an

\footnotetext{
${ }^{1}$ A good starting place to survey work on differences in outcomes between the religious and non-religious is Johnson, Tompkins, and Webb (2002), which surveys nearly 800 articles and a host of outcomes. More recent surveys include Wallace, Myers, and Osai (2004) who survey work on religion and substance abuse; Regnerus (2003) who surveys work on religion and various outcomes for adolescents; Ferguson, Wu, Spruijt-Metz and Dyrness (2007) who survey work faith-based social service provision; Marks (2005) who surveys work on religion and various health outcomes; Wong, Rew, and Slaikeu (2006) who survey work on adolescent religiosity and mental health; Dew et al. (2008) who survey work on religion and adolescent psychiatric symptoms; Rew and Wong (2006) who survey work on adolescent health and religion; Johnson (2008) who discusses work on prisoner recidivism and religion; and Lillard and Price (2007) who discuss work on religion and outcomes for youth in disadvantaged families.
} 
instrumental variable that affects religiosity but does not otherwise affect outcomes of interest. But there is no accepted instrumental variable for identifying the importance of any aspect of religious practice. Altonji, Elder, and Taber (2005) (who look at religious education), Hungerman (2010) (who looks at religious markets), and Lillard and Price (2007) (who look at religious practice more generally) all review instruments or other identification strategies that have been proposed to study religion and in each case the authors find that available identification strategies have serious limitations.

The goal of this paper is to consider the impact of religious proscriptions and rules on adherents' behavior. Instead of pursuing an instrumental variables strategy, this paper develops an empirical approach based on the club-goods model developed by Laurence Iannaccone (1992). A critical feature of the model is that it offers an explanation both for how rules and proscriptions could matter and how, in that case, individuals could benefit from facing them. The model provides conditions under which rules that limit behavior in a religious club will create efficiency gains; I find that these conditions allow both for situations where proscriptions have an important effect on behavior and situations where they do not, but that these two types of situations can be distinguished. I use this insight to empirically investigate whether proscriptions matter.

More specifically, the model depicts religious organizations as clubs whose members undertake both religious and secular consumption. An individual's religious consumption creates external benefits for others in the club; clubs consequently face a potential free-rider problem where members will overconsume secular goods and under-consume religion. Clubs can counteract this problem by proscribing their members' behavior — for example, forbidding excessive drinking or mandating that members refrain from labor activities on the Sabbath. A simple but critical insight of the model is that such rules change the opportunity cost, or price, of secular consumption. Members of a religious club thus face different incentives than other individuals: for the religious, proscribed secular activities are more costly. Given the club’s free-rider problem, such price increases can actually improve member utility.

I show that two key factors determine whether price increases are beneficial. The first factor is the utility members receive from the religious club relative to the utility received from secular 
consumption. Price increases can create utility gains if members derive high utility from the religious club and low utility from secular activities; members with these preferences will be especially willing to face higher costs of secular activities (which they place little value on anyways) in order to solve the free-rider problem. Price increases can thus create utility gains even if members have little interest in secular consumption and religious proscriptions have little impact on members' behavior. The model thus allows for a "correlation" situation, where the empirical association between religion and other outcomes reflects a correlation of preferences rather than a strong direct effect of religious participation on behavior.

The second factor that allows price increases to raise utility is the extent to which members view proscribed secular activities as substitutes for religious activity. If these activities are highly substitutable, price increases from religious rules will have important impacts on behavior: they will create utility gains by inducing members to substitute out of secular consumption and into religious consumption. Thus in addition to the "correlation" situation, the model also allows for a "causal situation” where religious proscriptions affect members’ decisions and outcomes.

The model thus predicts that highly religious individuals will undertake less binge drinking and other prohibited behavior. However, the model allows both for a situation where members are unresponsive to religious rules about secular consumption and a situation where members are very responsive. The latter situation—where religious groups have a causal effect on behavior — has the distinct and counterintuitive implication that the highly-religious will be individuals whose behavior is highly marginal; these individuals view secular and religious activities as substitutes and changes in the incentives to undertake secular activities will have large effects on their decisions. An empirical test of whether highly-religious individuals are responsive to secular incentives can provide evidence for (or against) this latter situation. Importantly, it is variation in secular incentives that is required; from an econometric standpoint, exogenous variation in religiosity (i.e., an instrumental variable for religion) is not needed.

In the second part of the paper, I consider a battery of tests of whether highly religious individuals are responsive to secular incentives. I define "highly religious" using both denominational strictness and 
ex-ante measures of religious consumption. To measure responsiveness, I consider changes in attendance, religious spending, and heavy drinking. I use three sources of variation in secular incentives: changes in blue laws, casino openings, and variation in minimum legal drinking age laws.

In every case but one I find strong evidence that highly religious individuals are in fact very responsive to changes in secular incentives. For example, I find that young adults who attend religious services at least weekly have much lower rates of heavy drinking than others-but upon reaching the legal drinking age, the likelihood that these individuals become heavy drinkers increases by nearly 10 percent. Results using other changes in incentives produce similar findings; for example, churches in the most conservative denominations see a 1 percent fall in spending when a nearby county opens a casino and the fraction of individuals reporting weekly-or-greater worship attendance falls by 4.5 percentage points when blue laws are repealed. Thus while highly religious individuals engage in lower levels of certain secular activities and willingly join organizations that discourage these activities, they are highly responsive to incentives to engage in these activities. Evidence that highly-religious individuals are very responsive to secular incentives is found when considering different behaviors, different measures of religiosity, different kinds of price changes, different datasets, different specifications, and across different time periods and populations for study. Strikingly, in many specifications highly religious individuals are more responsive than anyone else to changes in blue laws, casino availability, or the legal drinking age.

I discuss in the conclusions possible settings where work such as this could be extended, including extensions to other social clubs that emphasize proscriptions and rules, such as criminal gangs, terrorist organizations, fraternities, communes, and political groups. For several reasons, the methodology here might face type-II error: even if there were little evidence of substitutability, one might argue that religious organizations could still have important direct effects on behavior that this methodology would not identify. But the empirical results presented here show that substitution can in fact be found in various situations.

The paper proceeds as follows. Section 2 lays out the model and the theoretical foundation for the 
empirical methodology. Section 3 discusses the sources of secular incentives to be used. Section 4 reports specifications and empirical results. Section 5 concludes.

\section{The Model}

The model is based off Iannaccone (1992). The analysis below adds nothing substantial to the theory; instead, the contribution here is to recast Iannaccone’s central result in a way that generates a useful empirical test that is not obvious from the original derivation. Those unfamiliar with the model may wish to consult Iannaccone (1992, 1994, 1996); these papers provide excellent rationale for many of the model's features. Other studies have discussed enriching Iannaccone's model, including Berman (2000), Makowsky (forthcoming a, b), McBride (2007) or Finke and Stark (2006).

There are several reasons that the club-goods model is a natural choice for exploring religious rules and proscriptions. First, this model is the best-known microeconomic model of religious behavior. Makowsky (forthcoming b) argues that Iannaccone’s model may be "the most successful and frequently employed” model in economics and religion and Lazear (2000) cites Iannaccone’s 1992 work as helping to create a newly established school of thought among those who research religious participation.

Second, the club-goods model accurately fits a number of empirical facts on religious behavior. For instance, the basic model (and some slight variations) have been used predict that strict religious groups should demand "sacrifices” from members or stigmatize members, that strict congregations will have higher participation (Iannaccone, 1992), that strict congregations will be smaller \& attract those with more limited outside options (e.g., lower wages, schooling) (Argyle and Beit-Hallahmi 1975, Berman, 2000), and that conversion will be more common/radical for strict congregations (Levine, 1984; Roof and McKinney 1987). The model has also been applied to a variety of different faiths and in a variety of different settings. But the empirical test proposed here has not been explored by previous research.

Third, the model is able to match a number of disparate facts specific to religious proscriptions and outcomes. The results from the model here generate several implications: (a) religious groups will prohibit certain secular consumption, (b) members of religious groups will consume less of the prohibited 
secular goods than others, and (c) the causal channel between (a) and (b) depends upon whether members are willing to substitute secular and religious consumption. Points (a) and (b) are well-noted, but (c) is not; the empirical tests below thus focus on this final novel implication of the model. But it is noteworthy that the model fits the large literature showing that religious groups forbid certain consumption and that religious individuals realize different consumption than others.

Fourth, beyond fitting several empirical facts related to religiosity and outcomes, the model can also explain why religious proscriptions could both matter for behavior and simultaneously benefit religious adherents. Fifth, the model is prima facie a natural choice for the topic here in that the model was originally developed to explain the existence of religious rules and regulations. The impetus of the model is that religious organizations are largely voluntary, and yet many religious organizations make strong and seemingly irrational demands of their members. The discussion here will be especially concerned with religious demands that impinge on economically relevant secular behaviors and outcomes.

There are a number of examples. For instance, many religions argue for a Sabbath day wherein members should voluntarily refrain from productive labor activities. To quote the $4^{\text {th }}$ Commandment: "Remember the Sabbath day by keeping it holy. Six days you shall labor and do all your work, but the seventh day is a Sabbath to the Lord your God”. Muslims have a similar obligation to "drop all business" for Friday prayer, although Friday prayer is not the same as the Sabbath.

Many religious traditions also argue against excessive alcohol consumption or any alcohol consumption at all. To quote the religious text Isaiah 5:22: "Woe to those who are heroes at drinking wine and champions at mixing drinks." Similarly, in the Qur'an: "In them (alcohol \& gambling) is a great sin, and (some) benefit for men, but the sin of them is greater than their benefit.” Religious groups which prohibit alcohol altogether include the church of Latter Day Saints (the Mormon Church), many traditions in Islam, Sikhism, Seventh-Day Adventist, and some groups in Buddhism, Hinduism, and Protestantism. Beyond religious texts, religious groups may attempt to enforce these beliefs through the timing of religious services, promoting social interactions that make subterfuge difficult, and through social 
activism. The model presented here depicts such religious actions as changing the price of secular consumption and shows that these price changes may be utility-increasing in the face of a free-rider (sometimes called an "easy-rider”) problem. The model also shows that these religious actions may—or may not—have a significant impact on adherent behavior. ${ }^{2}$

\section{A. Basic Model}

Consider a religious club of $N+1$ identical individuals. The assumption that individuals within a club are identical is mainly done for convenience. I discuss in the appendix extending the result to heterogeneity within clubs, and a situation with multiple clubs and different individuals is discussed more below. Each club member $i$ derives utility from three things: secular consumption $S^{i}$, individual $i$ 's religious participation $R^{i}$, and the overall “quality” of the club, $Q^{i}$ :

$$
U^{i}=U\left(S^{i}, R^{i}, Q^{i}\right)
$$

where $U$ is twice continuously differentiable, strictly quasi-concave, and strictly increasing in all its arguments. ${ }^{3}$ Individuals choose their secular and religious consumption subject to a budget constraint:

$$
\pi_{s} S^{i}+\pi_{r} R^{i} \leq I^{i}
$$

where $I$ is endowed resources and prices are given by $\pi_{s}$ and $\pi_{r} \cdot{ }^{4}$ Group quality, which individual $i$ takes as given, is determined by:

$$
Q^{i}=F\left(\bar{R}^{i}, N\right)
$$

where $\bar{R}^{i}=\sum_{k \neq i} \frac{R^{k}}{N}$ is the average level of $R$ for all club members other than $i$. Assume that the technology $F$ is twice continuously differentiable, concave, and increasing in its arguments. Thus

\footnotetext{
${ }^{2}$ Some religious traditions take these prohibitions more seriously than others; this is discussed more below.

${ }^{3}$ For simplicity, the analysis here focuses only on consumption of $R, S$, and $Q$. If individuals received utility from additional goods $X_{1}, X_{2}$, up through $X_{k}$, the main intuition developed below from equation (6) would be preserved, and with some reasonable restriction on preferences, such as $U^{i}=U\left(\Gamma\left(S^{i}, R^{i}, Q^{i}\right), X_{1}, \ldots, X_{k}\right)$, all of the results developed below would follow.

${ }^{4}$ The equation is comparable to equation (4) in Iannaccone (1992). The model is easily adapted to both monetary and temporal resources at once; here the distinction is unimportant and readers can consider consumption as either in time or money.
} 
individuals' religious participation $R^{i}$ benefits others in the club, as it affects club quality for other members. Intuitively, individuals value being associated with a club where other members are dedicated to club activities so that the quality of worship service and social interaction is high. It is straightforward to show that this externality leads to a Nash Equilibrium outcome that is not Pareto optimal, as individuals fail to account for the external benefits from consuming $R^{i}$. The congregation may be able to address this inefficiency by raising the cost of secular activity, that is, increasing $\pi_{s}{ }^{5}$ To see this, consider a symmetric Nash Equilibrium. The typical club member's indirect utility function is given by

$$
V\left(I, \pi_{s}, \pi_{r}, Q\right)=\max _{R, S}\left\{U(S, R, Q) \mid \pi_{s} S+\pi_{r} R \leq I\right\} .
$$

Equilibrium quality $Q$ will satisfy the expression

$$
F\left[R\left(I, \pi_{s}, \pi_{r}, Q^{e}\right), N\right]=Q^{e}
$$

The equilibrium will be stable if $(\partial F / \partial \bar{R})(\partial R / \partial Q)$ is less than unity.

If the price $\pi_{s}$ increases, the equilibrium change in utility is:

$$
\frac{d U^{e}}{d \pi_{s}}=\frac{\partial V}{\partial \pi_{s}}+\frac{\partial V}{\partial Q^{e}} \frac{d Q^{e}}{d \pi_{s}}
$$

One can show that equilibrium utility will increase when the price of secular consumption rises if and only if the following inequality holds: ${ }^{6}$

$$
\varepsilon_{r \pi_{s}} \frac{U_{Q}^{e} Q^{e}}{U_{S}^{e} S^{e}}>\frac{1-\varepsilon_{F r} \varepsilon_{r q}}{\varepsilon_{F r}}
$$

where $\varepsilon_{a b}$ is the elasticity of $a$ with respect to $b, Q^{e}$ and $S^{e}$ are the equilibrium levels of $Q$ and $S$, and $U_{a}^{e}=\left.\frac{\partial U}{\partial a}\right|_{\substack{R=R^{e} \\ S=S^{e} \\ Q=Q^{e}}}$. The right hand side is an unobservable group-idiosyncratic expression governed by the

\footnotetext{
${ }^{5}$ One might also wonder whether congregations could address this issue by lowering $\pi_{r}$ (subsidizing religion); this may be impractical for a number of reasons, including the fact that true religiosity may be hard to observe.

${ }^{6}$ The appendix shows how to derive (6) from (5).
} 
group technology and stability ensures that the right hand side of (6) is positive. The left-hand side of (6) shows that there are essentially two factors which determine when a congregation can raise welfare by increasing the costs of secular activities, a ratio of utilities and the elasticity $\varepsilon_{r \pi_{s}}$.

Consider first the ratio $\frac{U_{Q}^{e} Q^{e}}{U_{S}^{e} S^{e}}$. The numerator of this ratio is the marginal utility of club quality in equilibrium, multiplied by equilibrium quality. This gives a first-order approximation of utility derived by quality in equilibrium. The denominator of this ratio represents utility derived from secular consumption. If the expression in (6) is driven by members having large values of this ratio, then the religious group could efficiently raise prices even if individuals are largely unresponsive to the price change-that is, the cross-price elasticity $\varepsilon_{r \pi_{s}}$ is small. Here the size of the group is fixed; relaxing this assumption would strengthen the result in (6) so that efficiency gains from a price increase would occur even if the cross-price elasticity were zero. ${ }^{7}$ In cases with a small or zero cross-price elasticity, individuals may attend strict religious organizations where the cost of secular consumption is high, but these individuals are not responsive to the strictness of the religious group. Intuitively, these individuals derive a high amount of utility from religious quality and are thus happy to have secular activities discouraged, as this results in an increase in group quality that they could not obtain on their own (since quality is taken as given). This is the correlation situation where members happen to "like” religion and “not like” secular consumption.

But there is a second term in (6), $\varepsilon_{r \pi_{s}}$. This shows that groups can profit from raising secular costs when members have especially large cross-price elasticities. In this case, members are extremely responsive to religious prohibitions; these individuals view secular and religious consumption as highly substitutable. A strict religious group can thrive with such individuals because the group gets a big "bang for its buck" when it raises the cost of secular activity: a change in $\pi_{s}$ results in a large change in

\footnotetext{
${ }^{7}$ This is because price increases in the more general case generate efficiency not only through substitution but also by "screening out" free riders. A case with multiple types sorting into groups will be considered below and is discussed in Iannaccone (1992) but the intuition related to screening is tangential to the analysis here.
} 
individuals' religious consumption and hence a large increase in the externality. In this situation, individuals are affected by religious participation; indeed, it is their responsiveness to religious advocacy that promotes efficiency when secular costs are raised. ${ }^{8}$

\section{B. Extension to Heterogeneity}

The above result from a single-club model thus suggests that behavior among the very religious might be driven by correlation in preferences or by a causal effect of proscriptions on behavior. Consider next extending this result to a situation with different individuals joining different clubs; this extension of the model is presented for three reasons. First, this analysis illustrates how high religious consumption and high proscriptions should be related in a setting where individuals can sort into different clubs. Second, this analysis confirms that the intuition developed for the single-club model can be extended to this more general setting. Third, this analysis clarifies what type of price effects can be used for empirical work.

The analysis here includes a proposition with three key conclusions: first, the proposition shows that clubs with relatively high levels of religiosity will have relatively high levels of religious proscriptions; second, the proposition shows that the efficiency gains created by higher proscriptions depend on (a) substitutability between $R$ and $S$ and (b) the utility provided by $Q$ and $S$ as discussed above; and finally the proposition shows that the more substitutable are $R$ and $S$ among those facing proscriptions, the more important are proscriptions in affecting secular behavior.

Suppose there are two types of individuals, a "high” type and a "low” type. For simplicity suppose that there are also two religious clubs; a low-proscription club that imposes a price of secular consumption of $\underline{\pi}_{s}$ and a high-proscription club that imposes price $\bar{\pi}_{s}>\underline{\pi}_{s}$. The utility of individual $i$ of

\footnotetext{
${ }^{8}$ There are several anecdotes that may help to capture the intuition of this result. One might regard the prediction of high substitutability as an "Alcoholics Anonymous" depiction of religion where religious groups may successfully make strong demands of their members (e.g., prohibiting drinking) because these members respond to the demands with intense religious devotion. See chapters 1 and 3 of Wilson (1955) for more on the role of religion in Alcoholics Anonymous. Another anecdote is the story of the "preacher's daughter," who after being raised in a strict religious upbringing engages in risky behavior upon leaving home. Another is the Amish tradition of "Rumspringa", wherein adolescents may choose to leave the Amish tradition and subsequently engage in illegal or unhealthy activities, as depicted in the film the Devil's Playground. The extent to which these stories reflect the model is debatable, but they may provide some intuition for the strong substitutability that drives the main result.
} 
type $j$ who joins club $k$ is $U^{i j}\left(S^{i}, R^{i}, Q^{k}\right)$, where quality in club $k$ is determined by club size and members' average religious consumption as in equation (2). Individuals are atomistic, and the population of each type of individual is normalized to unity. ${ }^{9}$ Individuals must make two decisions. First, individuals choose which club to join. Second, after the outcome of the first decision is observed, individuals simultaneously make their consumption choices for $S$ and $R$.

Consider a (stable) Nash Equilibrium outcome of this game; in any such equilibrium outcome it must be true that no individual would prefer to change their decision about which club to join. It must also be true that all individuals are making optimal choices of $S$ and $R$ given the club quality and prices they face. To motivate the empirical analysis, suppose there exists an equilibrium outcome with the following characteristics: first, all high-type individuals choose to join one club and all low-types choose to join the other club. Second, high types have higher religious consumption $R$ in equilibrium than low types. Finally, suppose for simplicity that choices of $R$ and $S$ are symmetric within clubs. ${ }^{10}$

The following proposition describes conditions that must hold in such an equilibrium outcome; in the proposition the term $U_{a}^{h}$ equals the marginal utility of high-types with respect to $a, R^{h}$ is the equilibrium choice of religious consumption for high types (and similarly for $S^{h}$ and $Q^{h}$ ), and $\left.\varepsilon_{a b}^{h}\right|_{\substack{R=R^{h} \\ Q=S^{h} \\ Q=Q^{h}}}$ refers to the elasticity of $a$ with respect to $b$ for high types evaluated at the equilibrium outcome.

Proposition: Suppose there are two types of individuals, high types and low types, and two religious clubs, a high-proscription club and a low-proscription club. Consider a Nash Equilibrium outcome where high types join one religious club and low types join the other club, consumption is symmetric within clubs, and religious consumption is greater for high types than for low types. Then the following hold:

\footnotetext{
${ }^{9}$ The appendix briefly discusses extending the basic model to non-atomistic individuals; doing so would not critically change the intuition here.

${ }^{10}$ Here we assume such an equilibrium exists; it is easy to provide examples of such an equilibrium in a simple model. Iannaccone (1992) discusses reasonable conditions that ensure the existence of sorting equilibriums where different types sort into different groups.
} 
(a) High type individuals will be in the high-proscription club.

(b) High types' marginal utility with respect to $\bar{\pi}_{s}, \frac{d U^{h}}{d \bar{\pi}_{s}}$, is increasing in both (i) the cross-price elasticity $\varepsilon_{r \pi_{s}}^{h}$, and (ii) the first-order approximation of utility from club quality, $Q^{h} U_{Q}^{h}$, and decreasing in the first-order approximation of utility from secular consumption, $S^{h} U_{S}^{h}$.

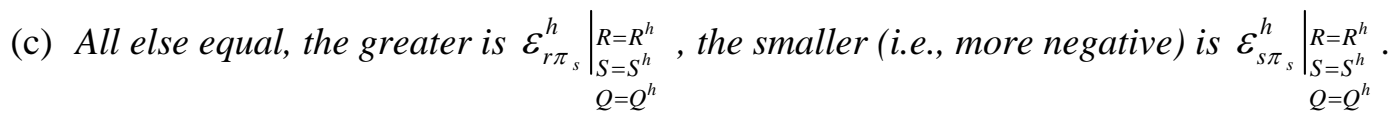

A proof of the proposition is given in the appendix. The intuition for these results is clear, however. For part (a), if high types are more religious, than the quality of their club will be higher. If quality were higher and prices were lower, then a separating equilibrium would not exist, as low-types would want to leave their own club and join the high-proscription club.

Part (a) of the proposition thus suggests that strict religious groups and high levels of participation go hand in hand. Prior work has indeed shown a tight connection between strict religious groups and high religious participation. Iannaccone (1994) describes the association between strictness and attendance (controlling for other covariates) as "truly astonishing” in magnitude (see also Dynes, 1955; Bibby, 1978; Harrison and Lazerwitz, 1982; Hoge and Yang, 1994; Iannaccone, 1988, 1992, 1998; and Olson, 2008). The behavior of highly religious individuals as defined either by group strictness or religious consumption should thus both be suitable for empirical tests, and the below empirical work will define "high types" both by using those with high (ex ante) religious participation and by using those associated with strict religious traditions.

Part (b) provides insight into what sort of preferences high types might have in order to make increased proscriptions efficient. The logic follows from the single-club case and the result could technically be applied to both low proscription clubs and high proscription clubs; however, parts (b) and (c) of the proposition are applicable to the high-proscription club as it is the high-proscription club that is 
charging the higher price. As in the single-club case, high valuation of club quality, low valuation of secular consumption, and high substitutability can all play a role in explaining efficiency gains for high types.

Finally, part (c) shows that greater substitutability corresponds to greater importance for religious proscriptions in affecting secular consumption $S$. The intuition for this final part of the proposition is also straightforward: if there is an increase in the price of $S$, then, all else equal, a large substitution response implies a large increase in $R$ compensated by a large decline in $S$. This intuition also holds for price changes in levels and not just elasticities.

The three parts of the proposition combine to suggest an empirical test for whether proscriptions matter: given a change in the cost of secular consumption, one could look for evidence that proscriptions matter by looking for evidence of substitution (a change in religious consumption) among the highly religious. ${ }^{11}$ But part (c) of the proposition also suggests a less circuitous test, which would be simply to estimate the own-price responsiveness of secular consumption; $\varepsilon_{s \pi_{s}}^{h}$. Given an empirical decrease in the price of secular consumption, evidence of an own-price effect-that is, an increase in secular consumption among the highly religious - would be evidence that incentives matter for these individuals.

Ideally both price effects - the own-price effect and the cross-price effect- could be studied, as the proposition suggests that these two price effects should be related. While evidence that adherents' secular consumption changes when prices change would show that incentives matter, it would be problematic if this evidence were not accompanied by a change in religious consumption as well, as the model uses a substitution effect to rationalize a price-sensitive individual's willingness to voluntarily face religious proscriptions. Thus the model shows that the relevance of proscriptions can be explored using data on either religious consumption or secular consumption alone, but preferably both would be used (and both will be considered below).

\footnotetext{
${ }^{11}$ Since the model assumes that religious groups can affect prices, one might wonder whether an exogenous shock to prices might elicit a response from religious groups that "undoes” the shock. The empirical work below relies on the idea that some shocks — such as a casino opening across the street, or the mall opening on Sundays — cannot be completely undone by congregations. To the extent that congregations can take unobserved (to the econometrician) actions to undo price shocks, observations of adherents' price sensitivity will produce estimates biased towards zero.
} 
This last part of the proposition also has implications for interpreting empirical results from such a test; this part of the proposition shows that evidence of substitutability among high types is evidence that proscriptions matter for high types. This part of the proposition holds for a given equilibrium outcome and does not involve a comparison of price sensitivity between high-types and low-types. In other words, the empirical test for substitutability should be based on absolute (not relative) price responsiveness among the highly religious, and evidence in a particular setting of substitutability would not be informative about the effects of proscriptions for other individuals or in other settings.

The implications of the test (and the model) are thus limited to the highly religious individuals for whom the model applies. Prior work has shown that different secular outcomes for religious individuals are often especially salient among the highly religious who adhere to strict, high-tension faiths (cf. Grasmick, Kinsey, and Cochran, 1991; Hammond, Cole, and Beck; 1993; Beyerlein, 2004; Berman, 2000; Cochran and Beeghley, 1991); this focus of the model on the highly religious is thus reasonable.

For some individuals (e.g., the non religious) the applicability of the model is limited, and for other individuals (those who may only be "moderately" religious) it may be unclear to an empirical researcher whether the model is applicable. ${ }^{12}$ Rather than make ad-hoc decisions about omitting arguably "moderate" individuals from the empirical results, the work below will include as broad a sample of observations as is possible in a given setting, but will obtain separate estimates of substitutability for different groups of individuals and will focus in particular on evidence of substitutability for the most religious for whom the model most clearly applies.

The estimates of substitutability obtained below will exploit several different changes in incentives; consistent results across a variety of changes in incentives will give confidence that sensitivity to secular incentives is a key but heretofore unexplored component of the model. Importantly, it is variation in incentives for secular consumption which will be used; the relative availability of exogenous variation in secular activities, combined with the general nature of the model, gives this test potentially

\footnotetext{
${ }^{12}$ Some work has tried to extend this model to "moderate” religious groups, cf. Makowsky (2010).
} 
broad applicability. ${ }^{13}$

The conditions which admit strict religiosity in inequality (6) and part (b) of the proposition may not be mutually exclusive; it could be that empirically there are both "correlation members" and "causation members" in the data at the same time. There is a chance in such a situation that the unresponsive correlation members could "drown out" the responsiveness of causal members, so that a researcher looking for evidence of causality could not reject the hypothesis that members are unresponsive to incentives even though in truth some members were responsive-type II error. The test described here is thus potentially low-power. ${ }^{14}$ The importance of this is likely situation-dependent and will be considered more below.

\section{Empirical Tests}

This section outlines a number of tests of whether highly religious individuals are responsive to secular incentives. In what follows I identify highly religious individuals using two separate criteria. First, I consider religious groups that prior research has identified as strict. Second, I consider the behavior of individuals who report high ex ante measures of religious participation—in particular, high attendanceseparately from individuals with low or moderate attendance. As the proposition in section 2 and empirical work discussed earlier show, both affiliation with strict groups and high ex ante participation should be suitable for studying responsiveness to secular incentives.

The test suggested by the model concerns changes in religious and secular consumption in response to changes in incentives for secular consumption. I consider three different sources of variation in incentives: blue laws (that impact incentives to engage in secular activities during the Sabbath), casino

\footnotetext{
${ }^{13}$ The test here is not so broad as to always relate substitution to causation, however. If two goods are substitutes, it generally would be incorrect to conclude from this that consuming more of one good causes one to consume less of the other good. At the risk of belaboring this point, here individuals inside a religious club face endogenouslydetermined incentives (i.e., prices) that are different from those outside of the club. Evidence of members' pricesensitivity can thus provide evidence of whether altered incentives matter for behavior.

${ }^{14}$ The model here focuses on changes in prices, but religious groups might also try to change preferences. To the extent that changes in preferences would result in greater preference for religious consumption and/or lower preferences for secular consumption, preference alterations would allow for efficiency gains even absent strong substitution, which would also work against the test proposed here.
} 
openings (that impact incentives to gamble), and minimum-legal-drinking-age laws (that affect incentives for underage drinking). I discuss each source of variation below.

\section{A. Blue Laws}

This subsection provides a brief overview on the history of blue laws in the United States. ${ }^{15}$ Blue laws refer to laws which restrict certain activities on the Sabbath. Laws banning general retail activityfor instance, by prohibiting "labor" or "all manner of public selling”—on Sundays were widespread as of the middle of the $20^{\text {th }}$ century. ${ }^{16}$ In 1961 the Supreme Court issued a number of decisions on the constitutionality of blue laws. The decision for the case McGowan v. Maryland upheld the constitutionality of blue laws, but stated that blue laws could be found unconstitutional if their classification of prohibited activities rested "on grounds wholly irrelevant to the achievement of the State's objective.” Blue laws were subsequently challenged on the basis that they did not satisfy this constitutional test (Theuman, 2005). These challenges were often successful because blue laws could be confusing in their classification of prohibited activities. For example, in New Jersey some counties allowed the sale of disposable diapers, but washable diapers were prohibited (King, 1976).

As blue laws are repealed, the cost of secular labor and leisure activities declines. Prior work has shown that the repeal of blue laws was associated with a decline in religious activities and changes in other activities, such as risky behavior and voting. ${ }^{17}$ Unlike prior research, the empirical work here explores the possibility that the marginal individuals responding to blue laws include those with the strictest and strongest religious devotion initially. Evidence of this would be evidence for an important role for religious proscription; prior work provides no insight on this critical issue. Additionally, of course, the main contribution of this analysis is developing a general methodology that does not concern blue laws per se but is applicable in many different situations, including both places and times where

\footnotetext{
${ }^{15}$ Additional discussion can be found in Cohen-Zada and Sander (2009); Hungerman (2010); Geber, Gruber, and Hungerman (2010); Goos (2005); Laband and Heinbuch (1987); and especially Gruber and Hungerman (2008).

${ }^{16}$ States sometimes exempted certain types of retail activity, for example allowing acts of charity or allowing pharmacies to stay open. Blue laws prohibiting specific types of activities, such as barbering or the sale of alcohol were also common but as with almost all prior research on blue laws the focus here is on regulation of general commerce.

${ }^{17}$ See Cohen-Zada and Sander (2009), Gruber and Hungerman (2008), and Gerber, Gruber, and Hungerman (2010).
} 
changes in blue laws occur as well as situations where such changes are unavailable.

Following prior work, I will examine the effect of blue laws using the sample of states that saw a discreet and significant change in the prohibition of retail activity on Sundays, or states that never had blue laws. There are 24 such states; they are listed below Panel A of Table $1 .^{18}$ This group of 24 states makes up a reasonably diverse group, with variation in the timing of laws and in the locations of the states themselves.

A concern with empirical work relating blue-laws' repeal to religiosity is that this work may be driven by underlying trends in religious behavior. ${ }^{19}$ Fortunately, most prior work on blue laws has established that the repeal of these laws does not seem correlated with underlying trends in religiosity or other observables in a way that might confound the analysis. Price and Yandle (1987) examine what economic and social factors are associated with the presence of state blue laws, including the political makeup of a state, the fraction of women in the workforce, the strength of labor unions, and other state socioeconomic characteristics; they found that none of their covariates were consistently associated with the presence of blue laws. Gerber, Gruber, and Hungerman (2010) and especially Gruber and Hungerman (2008) consider underlying trends and reverse causation in depth and find that blue laws' repeal seems unrelated to preexisting religious trends. However, the analysis below will also consider this issue by testing the specifications' sensitivity to various strong controls for trends. Further, the regressions using data from the National Longitudinal Survey of Youth will allow for a number of very demanding specifications including ones with year-by-state dummies and individual fixed effects. Fortunately, the findings here and in most past work suggest that blue laws are not driven by trends in religiosity.

\footnotetext{
${ }^{18}$ The most common reason a state is excluded from the analysis is that the state's laws were (or are) decided at the county or city level, making these states unusable with our state-level datasets. A few states were not used because the exact time that the laws were repealed is unverifiable. See Gruber and Hungerman (2008) for more detail on the selection of states. Dropping the 8 states that never had blue laws does not affect the results below.

${ }^{19}$ Also a concern is that blue laws may not have been enforced before to their repeal. Lack of enforcement will bias the empirical results towards zero, and prior work has shown that this is not a concern. Further, anecdotal evidence for a number of states indicates the significance of changes in the laws (a sample includes McGee, 1991; Reinhold, 1985; The New York Times, 1970; and the Associated Press, 1984).
} 


\section{B. Casino Openings}

The second source of secular variation used will be casino openings. Nevada was the only state with casinos up to 1978. Since then, and especially since the late 1980s, there has been a dramatic growth in the number of casinos in the United States. As of 1999, 28 states had legalized casinos (NGISC, 1999). In 1998, the majority of all legal gambling revenue in the United States was from casinos (Barron, Staten, and Wilshusen, 2002) ${ }^{20}$ and in 1999 nearly one third of Americans reported having gambled at a casino in the past year (NGISC, 1999)..$^{21}$

A 1987 Supreme Court decision, California v. Cabazon Band of Mission Indians, played a major role in the growth of casinos. ${ }^{22}$ Indian tribes are sovereign nations, and the Supreme Court ruling confirmed that states lacked the power to regulate commercial gambling on Indian reservations. The federal government responded to this ruling by clarifying the regulatory framework for casinos with the Indian Gaming Regulatory Act (IGRA) in 1988. This act divided gaming into three classes: Class I, social games "solely for prizes of minimal value" or traditional Indian games identified with ceremonies and celebrations; Class II, bingo and "other games similar to bingo;” and Class III, “all forms of gaming that are not Class I gaming or Class II gaming,” such as blackjack, slot machines, roulette, or other casino games. $^{23}$

Figure 1 shows the extraordinary growth in the number of counties with a Class III gambling establishment following this ruling. Figure 1 also shows a slight delay in this rise following the passage of the IGRA. This may reflect the fact that the IGRA stated that Class III gaming was allowed on reservations only if gaming had been agreed upon by a tribal state compact. There were in some cases delays as states and tribes established such compacts. ${ }^{24}$ Further, tribes can only offer Class III games

\footnotetext{
20 The term "gambling revenue" refers to gross dollars wagered minus dollars paid out in winnings.

${ }^{21}$ See Figure 1-2 in the NGISC report for reported gambling habits in the past year by selected types of gambling games.

${ }^{22}$ See Evans and Topoleski (2002) for an excellent discussion of this decision.

2325 U.S.C. 2701-2721; see § 2703 for these definitions.

${ }^{24}$ In a few instances, notably California, some tribes established gaming before a compact was actually completed. The IGRA placed the burden on states to bargain in good faith and stated that tribes could sue the state for not bargaining in good faith, although this provision of the law has been challenged in court.
} 
when states allow these games elsewhere, meaning not all states saw growth in casinos over this period. In some situations, such as in the state of Connecticut, whether a state allowed gaming elsewhere was a point of dispute leading to lengthy court cases. The Cabazon ruling and IGRA act thus led to considerable casino growth, but this growth was idiosyncratic across states and time.

Many major religious traditions advocate against the dangers of gambling, and have expressed concern about this recent growth. ${ }^{25}$ Research has also shown that religious individuals gamble less than others and that those attending religious services most frequently are much less likely to gamble heavily (cf. Diaz, 2000; Lam, 2006; Hoffman, 2000). The model in section 2 suggests that despite the low level of gambling among the religious, it could be that highly religious individuals would be willing to substitute gambling for religious consumption if the availability of gambling changed. The empirical work below will thus investigate whether the diffusion of casinos within a state lowers the religiosity of initially religious individuals. Work in the following section will also consider whether casino openings are predicted by underlying trends. Other work, considering non-religious outcomes, has found that casino openings have important impacts on surrounding areas. ${ }^{26}$

The data for casino availability here was provided by Earl Grinols and David Mustard, and was used in Grinols and Mustard (2006). The data report for every county in the United States whether a Class III casino is in operation and when the first Class III casino opened. The data used in their paper covered the period 1977 to 1996; for the present study the authors provided data for two additional years so the data here cover 1977 to 1998 . Their data includes tribal casinos as well as riverboat casinos, other land-based casinos, and "boats to nowhere" that travel outside of U.S. boundaries so passengers can

\footnotetext{
${ }^{25}$ The results below consider the response to casinos from 4 denominations: the Lutheran Church Missouri Synod, the Southern Baptist Convention, the United Methodist Church, and the United Church of Christ. At least three of these denominations have made explicit statements expressing concern over the rise of gambling following the Cabazon decision. The Office of the President of the Lutheran Church Missouri Synod (1999) issued a statement asking congregation lay leaders to communicate "the profoundly harmful impact that state-sponsored and legalized gambling is having on our nation and on our communities," the Southern Baptist Convention passed a resolution (1996) stating the church's "frequent opposition to the gambling industry and the devastating effects of gambling upon the moral and economic life of our nation;" the United Methodist Church (2004) has stated that "gambling is a menace to society" and "deadly to the best interests of moral, social, economic, and spiritual life."

${ }^{26}$ Grinols and Mustard (2006) show that casinos may be associated with higher crime rates, Evans and Topoleski (2002) and Wenz (2008) find that casino openings may increase employment, and Anderson (2009) finds that casino openings lower assistance income among low-educated female householders.
} 
gamble. If a Class II casino converts to a Class III casino, this is captured in the data as a new Class III casino. Evans and Topoleski (2002) show that there is considerable variation in the size of Class III casinos, with the median tribal casino having 450 slots and 27,000 square feet; while the biggest tribal casinos include some of the world's largest casinos, such as Foxwoods in Connecticut, with 5,700 slots and 315,000 square feet.

\section{C. Minimum Legal Drinking Age Laws}

A third source of variation in the cost of secular activities will be the Minimum Legal Drinking Age, or MLDA. Following the passage of the $21^{\text {st }}$ amendment in 1933, most states imposed a 21-year age minimum for the purchase and possession of alcohol (Rooney and Schwartz, 1977). In the early 1970s, however, over half of all states lowered the minimum age for the purchase of alcoholic beverages. A number of research studies suggested that these changes led to an increase in fatal car accidents, ${ }^{27}$ and in the late 1970s some states began to re-raise the MLDA (Du Mouchel, Williams, and Zador, 1987). In 1984, the federal government enacted the Uniform Drinking Age Act, which provided for the withholding of 5 percent of highway aid from states not having a minimum alcohol purchase age of 21 for all alcoholic beverages by October 1, 1986; 10 percent of funds would be withheld from states not having a minimum purchase age of 21 in 1987. By 1988, all states had established an MLDA of age 21 (Wagenaar and Toomey, 2002).

A large amount of research has explored whether these laws impacted youth drinking and youth health outcomes. While some studies are inconclusive, Wagenaar and Toomey (2002) exhaustively review prior work and conclude that "compared with a wide range of other programs and efforts to reduce drinking among teenagers, increasing the legal age for purchase and consumption of alcohol to 21 appears to have been the most successful effort to date.” Weschsler, Lee, Nelson and Kuo (2002) also conclude that "the minimum legal drinking age (MLDA) law may be the single most effective method to

\footnotetext{
${ }^{27}$ For instance, Williams et al., (1975), Cook and Tauchen (1984), and Smart and Goodstadt (1977).
} 
combat alcohol use and its adverse consequences among young people.”28 Carpenter and Dobkin (2009) use a regression discontinuity analysis to show that MLDA laws reduce drinking by 11 to 21 percent, a large effect.

Work has shown that highly religious individuals are less likely to drink heavily than others, and that religious affiliation is a predictor against alcohol abuse among adolescents (cf. Johnson, Tompkins, and Webb, 2002, and see below). The model from section 2 indicates that this empirical relationship may be driven by religious adolescents having a low taste for drinking or because religious adolescents substitute out of drinking in response to religious instruction. Evidence that religious youth are highly responsive to minimum legal drinking age laws would be evidence for the latter scenario.

For this empirical test, data on MLDA laws were taken from O’Malley and Wagenaar (1991) and verified against other sources, including Du Mouchel, Williams, and Zador (1987). The laws are for the minimum legal purchase age for any alcoholic beverage. The data used here account for the fact that some states included "grandfather clauses" in their laws, so that if the MLDA was raised to 21, an individual just under age 21 who had already reached the prior legal drinking age would maintain the ability to purchase alcohol. The main data for testing these laws (described more in the next section) will be the 1979 National Longitudinal Survey of Youth, a survey of individuals 14 to 22 in 1979. The NLSY's time period and sample are fortuitous given that the early 1980s saw a large number of MLDA law changes and many of these changes affected cohorts in the NLSY sample. Furthermore, MLDA laws affect some individuals in a given state and year but not others; this plus the panel nature of the NLSY will allow for very strong specifications to control for any omitted phenomenon that might be associated with changes in MLDAs.

To summarize, the work below will pursue three different sources of variation in incentives for secular activity: blue laws, casino openings, and minimum drinking age laws. All of these sources of variation affect activities that prior work suggests might (or might not) substitute for religious behavior.

\footnotetext{
${ }^{28}$ Other methods of deterrence might include greater enforcement or taxation. Grossman, Chaloupka, Saffer and Laixuthai (1994) provide a discussion of these various deterrence methods, although they state that increases in the legal drinking age have been "the major element of programs to deter adolescent alcohol abuse."
} 
In all three cases the variation in incentives is largely driven by state legislation, federal court rulings, federal legislation, or all three. Furthermore, the three tests are varied in their time periods of secular change (from 1955 to 1991 for blue laws, the 1990s for casinos and the early 1980s for MLDAs), varied in the populations and states affected, and varied in whether they made secular activities more attractive or less attractive. Consistent evidence across all three tests would thus provide compelling evidence for or against the ability of religious proscription to change the behavior of members.

\section{Results}

This section presents evidence of whether religious individuals respond to secular incentives. The variation in secular incentives will come from blue laws, casino openings, and the minimum-legaldrinking-age. Religious individuals will be identified by denominational affiliation and prior religious attendance. The outcomes used for testing responsiveness will include religious spending, religious attendance, and heavy drinking. The results are organized by outcome; the first subsection presents specifications and results for testing the model by using data on religious spending

\section{A. Results from Religious Spending}

This subsection reports results from religious spending, a suitable measure of congregations' financial resources and one strongly related to other measures such as donations (Hungerman, 2008). The data on religious spending are the same as in Gruber and Hungerman (2008) and are taken from denominational yearbooks for the second half of the twentieth century. The data cover four denominations: the Lutheran Church Missouri Synod, or LCMS (this was the $7^{\text {th }}$ largest denomination in the country in 1971, near the midpoint of the sample); the Southern Baptist Convention, or SBC $\left(2^{\text {nd }}\right)$, the United Church of Christ, or UCC $\left(9^{\text {th }}\right)$, and the United Methodist Church, or UMC $\left(3^{\text {rd }}\right) .^{29}$

These four denominations may not be representative of all churchgoers. However, they are all among the largest denominations in the country, and are all fairly widespread. Panels A and B of Table 1 show the years and states available for each denomination in these regressions. There is wide coverage

\footnotetext{
${ }^{29}$ Data on denomination size come from the Glenmary Research Center (1974).
} 
over place and time. Utah is the only state repealing a blue law that is unavailable and the regressions on casino openings include 45 states (missing states are listed under panel B). For most states there are multiple observations. One cautionary note is that data for the LCMS denomination are only available up through 1991, which is just before the strong growth in casinos. Data from the LCMS should be interpreted with caution when examining the casino regressions. ${ }^{30}$

These denominations also vary in their strictness. McBride (2007), Iannaccone (1994), and Hoge (1979) all discuss the relative strictness of these denominations and all present evidence that the Southern Baptist Convention is the strictest, followed by the Lutheran Church Missouri Synod, the United Methodist Church, and the United Church of Christ. Hoge's study is based on a questionnaire sent to a group of experts including church historians, sociologists of religion, denominational and ecumenical leaders, and seminary educators. ${ }^{31}$ Iannaccone (1994) argues that one question in the survey is especially relevant to ranking denominations in the context of the model; this question asked experts to rank denominations based on "whether the denomination emphasized a distinctive life-style or morality involving such matters as dress, diet, drinking, entertainment, use of time, marriage, sex, childrearing, and the like;" the experts ranked the SBC, LCMS, UMC, and UCC from most to least strict in that order. Furthermore, experts consistently ranked the SBC as one of the strictest large denominations in America, and the UCC as one of the least strict. ${ }^{32}$ The four denominations here thus represent a broad spectrum of strictness among large denominations.

The regressions will investigate whether church resources, as measured by total spending, change in response to blue laws and casino openings. ${ }^{33}$ For blue laws the baseline regression is:

$$
\text { lspend }_{d s y}=\gamma \text { denom }_{d} * \text { repeal }_{s y}+\beta X_{s y}+\phi_{d y}+\theta_{d s}+\varepsilon_{d s y} \text {, }
$$

where, for denomination $d$ in state $s$ in year $y$, the variable lspend is the log of total per member spending

\footnotetext{
${ }^{30}$ There is at least some variation in the LCMS data, however. New Jersey has casinos starting in 1978 and by the final year in the LCMS data, 1991, there are 7 LCMS states with at least one casino.

${ }^{31}$ See endnote 4 in his paper for a complete list.

${ }^{32}$ Among very large denominations, the only one ranked as more strict than the SBC was the Church of Latter Day Saints, and the only one ranked less strict than the UCC was the Episcopal Church.

${ }^{33}$ Since the data here cannot be broken down by churchgoer age, and since MLDA laws directly affect only younger adherents, the tests with spending data will focus on blue laws and casino openings.
} 
by a church, repeal is a dummy that equals unity if a state has repealed its blue laws, denom $_{d}$ is a set of dummy variables for each denomination, $X$ is a set of controls, $\phi_{d y}$ is a set of denomination-by-year dummies, and $\theta_{d s}$ is a set of denomination-by-state dummies. The controls in $X$ include the rate of insured unemployment, the fraction of the population foreign born, per capita disposable income, the percent of the population black, the percent of the population under age 5, ages 6-18, ages 45-64, and over 64. The set of dummies in $\phi_{d y}$, which would subsume a simple set of noninteracted year or denomination dummies, allow each denomination’s spending to follow its own nonlinear trend over time. The set of dummies in $\theta_{d s}$ allow for different levels of spending across states for each denomination. The unit of observation is all churches within a denomination, in a given state and year. The coefficients of interest in the above regression are the set of coefficients in the vector $\gamma$; these coefficients show, for each denomination, how spending in the denomination changed after repeal relative to spending in the denomination before repeal. The set of dummies in denom $_{d}$ includes a dummy for each denomination, meaning a separate (uninteracted) repeal dummy does not need to be included in the specification (and cannot be, because of collinearity).

For the regressions on casinos, the above specification will be slightly altered to estimate

$$
\text { lspend }_{d s y}=\gamma \text { denom }_{d} * \operatorname{casinos}_{s y}+\beta X_{s y}+\phi_{d y}+\theta_{d s}+\varepsilon_{d s y} \text {, }
$$

where the variable casinos represents the number of counties in a state operating a Class III gaming establishment. The samples used for estimating equations (7) and (8) are given in panels A and B of Table 1.

Table 2 reports estimates for equation (7). Robust standard errors, clustered by state, are reported in brackets. Regressions weight observations by church membership and all monetary figures are in year 2000 dollars. The first column reports results with only Southern Baptist Churches - the strictest churches-included in the sample. The results indicate that, when blue laws are repealed, religious spending falls by about 5 percent relative to its prior level, and the decline is statistically significant. The 
next column adds in all denominations; here the repeal dummy is interacted with a dummy variable for each denomination; this provides an estimate of the effect of repeal for each denomination.

All of the estimates are negative, suggesting a fall in spending as blue laws are repealed, but only the SBC and LCMS estimates have any statistical precision. There are alternate ways to interpret the lack of precision for the UMC and UCC observations. On the one hand, especially for the UMC, one might argue that members of this denomination face strict religious proscriptions and thus the model used in section 2 applies to their behavior; in this case the evidence in Table 2 could not rule out the possibility that these adherents are "correlation” members. Alternately (perhaps more plausibly), one could argue that these relatively "liberal" denominations do not impose restrictive proscriptions and rules on members, in which case the imprecision in Table 2 says little about the importance of proscriptions for these individuals. But more importantly, the results do suggest responsiveness among the strictest faiths, which is noteworthy as these faiths are the most compatible with the model and (as discussed earlier) have adherents whose secular behavior and outcomes are the most distinct.

The set of denomination-by-year and denomination-by-state dummies in column 2 is strong, but one can further investigate whether underlying trends are affecting the results by including state-specific time trends. Column 3 adds in state time trends; this addition has little impact on the estimates. The final column considers a stronger specification with state-by-denomination trends; again the results are qualitatively similar.

Table 3 presents estimates of equation (8) for the regressions on casinos. The results are similar to those in Table 2 and continue to indicate that churches of strict denominations see declines in spending when casinos open. The first column in Table 3 again considers only the strictest denomination, the SBC, and the results indicate that SBC spending falls about one percent for every county which opens a Class III casino. Column 2 includes all denominations, allowing the effect to vary for each denomination. As before, columns 3 and 4 add in state trends and state-by-denomination trends, and as before the results are generally similar regardless of these controls, although one notable change in column 4 is that the effect of casinos on LCMS congregations becomes negative and statistically significant. At in Table 2, the 
strongest specification in column 4 here shows a pattern where an increase in strictness is actually associated with a greater response to casino openings. Table 3 thus indicates that the two strictest denominations - the SBC and LCMS—have members who display cross-price responses as Class III casino gambling becomes more readily available.

The overall result from Tables 2 and 3 is that strict denominations respond to changes in secular incentives. This fits with the scenario depicted in the model where individuals view strict religious adherence and secular opportunities as substitutes and thus religious proscriptions and other changes to incentives will matter for behavior. The next subsection considers the effects of blue laws and casino spending on religious attendance.

\section{B. Results from Religious Attendance}

The attendance data here will be taken from 1973-1998 waves of the General Social Survey, the longest-running nationally representative survey that regularly asks questions on religious attendance. Unlike the data used in the prior subsection, here the data include individuals from a national sample and will reflect a variety of religious traditions. The GSS is a (roughly) biennial survey that asks individuals how often they have attended religious worship in the prior year. The GSS is a repeated cross section, not a panel or longitudinal study.

As with spending, the tests here will examine how attendance responds to blue laws and casino openings. The specification to test the effects of blue laws is:

$$
\operatorname{atd}_{i s y}=\delta^{*} \text { repeal }_{s y}+\beta X_{i s y}+\theta_{s}+\varphi_{y}+\varepsilon_{i s y}
$$

where, for individual $i$ in state $s$ and year $y$, the variable atd represents a measure of religious attendance, the variable repeal is a dummy for whether a state has repealed its blue laws, $X$ is a set of controls, $\theta_{s}$ is a set of state dummies, and $\varphi_{y}$ is a set of year dummies. The controls in $X$ include both individual controls for socioeconomic characteristics (respondent's gender, race, educational status, marital status, dummies for age), and state controls (the percent of individuals in the respondent's state black , the percent foreign born, the rate of insured unemployment, and per capita disposable income). 
Estimates of (9) will be reported for three different dependent variables. First, the dependent variable will equal unity if an individual reports high attendance-weekly attendance or more-and equal zero otherwise. Second, the dependent variable will be a dummy for low attendance, the variable will equal unity of a respondent reports attendance in the past year that is less than weekly but more than never (and the variable will equal zero otherwise). Third, the dependent variable will be a dummy for no attendance; the variable will equal unity if a respondent reports no attendance (and equal zero otherwise). These three categories will make the GSS results comparable to the NLSY results reported in the following subsection.

The variable $\delta$ will show how the repeal of blue laws impacts the likelihood that an individual reports being in any given attendance category. If the coefficient $\delta$ is negative when the dependant variable is a dummy for high attendance, this would indicate that blue laws' repeal lowers the likelihood that individuals report high attendance and would be consistent with highly religious individuals substituting religious consumption with secular opportunities. An insignificant or positive $\delta$ coefficient would be evidence against this scenario.

The GSS regressions on blue laws will limit the sample to Catholics and Protestants (those who worship on Sunday and presumably are affected by the laws) and again will use the states listed under Panel A of Table 1. Panel C of Table 1 shows selected means from the GSS, about 30 percent of respondents attend weekly, about 57 percent between weekly and never, and about 14 percent report never attending.

The regressions on casino openings will be similar to the blue laws regressions, except that here the sample can include all individuals in all states:

$$
\operatorname{atd}_{i s y}=\delta^{*} \operatorname{casinos}_{s y}+\beta X_{i s y}+\theta_{s}+\varphi_{y}+\varepsilon_{i s y}
$$

where all variable are as in equation (9) except for the key regressor casinos, which will equal the number of counties with a Class III casino operating in the state.

The results from linear probability estimates of equations (9) and (10) are given in Table 4. 
Again, standard errors are robust and clustered by state. Panel A reports estimates from the blue laws specification. The first pair of columns shows the estimated coefficient for $\delta$ when the dependent variable is a dummy for high (weekly or more) attendance. The coefficient in column 1 is negative and significant, showing that there is a fall in weekly or greater attendance when secular opportunities increase on Sunday. The estimated 4.5 percentage point decline in the likelihood of weekly attendance is modest but nontrivial. Column 2 shows that inclusion of trends makes this result stronger; the result clearly indicates that high levels of religious participation are affected by secular incentives. The coefficients in columns 3 and 4 show that this fall is compensated by an increase in low attendance and (to a lesser extent) the last pair of columns shows an increase in non attendance.

The second panel of Table 4 shows results from the casino regressions. While the baseline coefficient on weekly attendance here is negative, it is small and insignificant, as are the low attendance and no attendance regressions. Adding trends produces qualitatively similar estimates. Overall, the estimates suggest that casino openings do not impact religious attendance.

The insignificant effects from panel B stand in contrast to the results in Tables 2 and 3 and panel A of Table 4. This might partly be because highly religious individuals do not view casino gaming and religious attendance as substitutes (although the earlier results suggest that they do view gaming and religious spending as substitutes). This could be an instance of type II error, as discussed earlier. Alternately, there may be measurement error in the independent variable casinos. Grinols and Mustard (2006) show that casinos have important impacts on their own communities but have weaker or negligible effects on neighboring counties. If most individuals in the GSS are located in communities without casinos, it could follow that the aggregate data used in the spending regressions captures the local effects of casinos but that the GSS data largely miss these effects. From 1993 on, only about 10 percent of GSS respondents live in a county with a casino. ${ }^{34}$ If the sample size of the GSS were large enough, it might be possible to find an effect using regressions based on county of residence to identify exposure to casinos,

\footnotetext{
34 The fraction living near a casino cannot be calculated for earlier years (county of residence is not available before 1993), but would be much smaller as casino prevalence was much lower in the 1970s and 1980s.
} 
rather than state of residence. Unfortunately, county information is only available for a few years (1994, 1996, 1998, and some of 1993), with the number of respondents in these years reporting that they live in a county with a casino ranging from a few dozen to a few hundred. The local effect of casinos combined with the small sample size of the GSS may thus mask the impact of casinos on religious attendance.

Overall, the results from Table 4 show that high levels of attendance drop in response to increased secular opportunities. As with the results on church spending, this suggests that strict religious members view secular and religious opportunities as substitutes. However, the results on casinos and church attendance are imprecise. The next subsection presents tests based on heavy drinking data.

\section{C.Results from Heavy-Drinking Data}

Data on heavy drinking will be taken from the 1979 National Longitudinal Survey of Youth, or NLSY. The NLSY is a nationally representative survey begun in 1979 with a sample of 12,686 respondents aged 14 to 22 . The initial wave of the NLSY asked respondents about their religious participation, and subsequent waves asked individuals about their alcohol consumption. The results here are from the 1983, 1984, 1985, 1988, 1989, and 1994 waves, which all included questions on alcohol consumption.

The 1979 wave of the NLSY included a question on the frequency of attendance, and answers were coded into a set of categories. Individuals will be grouped into categories comparable with those used in section 4B: those reporting weekly or greater religious attendance (high attendees), those reporting attendance less than weekly but more than never (low attendees) and those reporting no attendance. Individuals in subsequent waves were asked whether they had consumed six or more alcoholic drinks on one occasion in the past month; this question will serve as the measure of heavy drinking. Panel D of Table 1 shows that about a third of the sample report high attendance, about half report low attendance, and about a sixth report no religious attendance.

Panel D also shows that about a third of respondents report heavy drinking in the past month, although this differs by religious attendance. Rates of heavy drinking are lower for high attendees (29 percent) than for low attendees (36 percent) or non attendees (40 percent). The fact that the strongest 
attendees have the lowest levels of drinking could indicate that religious participation discourages drinking or that these individuals have low tastes for drinking. Evidence that religious individuals drink more when incentives change would be evidence against the latter scenario. This subsection considers two changes in incentives: blue laws and the legal drinking age. Both changes may matter for heavy drinking, but one caveat with the blue laws regressions is that only a small number of states repealed blue laws after 1982: Minnesota, North Dakota, South Carolina, and Texas.

The NLSY regressions are based on a panel; since the data are at the individual level, one can compare differences in the behavior of individuals in the same state and year. To exploit these features, the estimates will be based on the following differenced regression:

$$
\Delta \text { had6 }_{\text {isy }}=\text { rattend }_{i} * \Delta \text { repeal }_{\text {sy }}+\beta \Delta X_{\text {isy }}+\Delta \varepsilon_{\text {isy }} \text {, }
$$

where for individual $i$ in state $s$ in year $y$ the variable had 6 is a dummy for heavy drinking and the variable $\Delta$ had 6 is the difference between the heavy-drinking dummy from the year in question and the prior interview year, attend is a set of three dummy variables for high, low, or no attendance in 1979, Arepeal is the difference in the repeal dummy between the current year and the prior interview year, $\Delta X$ is a set of individual controls including change in marital status or educational attainment from the prior interview, and state controls including the percent of the state that is black, percent foreign born, per-capita disposable income, and the rate of insured unemployment (these state variables are included in levels and in first differences, although the results with state-by-year dummies show that these controls are unimportant), a set of age dummies, and a set of dummies for years since the prior interview.

The key coefficients of interest in the above regression are in the vector $\gamma$, the set of coefficients for the variables interacting initial religiosity with a change in blue laws. (Since our three attendance categories include all respondents, there is no need to include a noninteracted repeal variable in this regression as it is subsumed by the interaction terms.) The attendance measures are taken from the initial survey year. Thus the interacted terms here reflect how changes in blue laws affect changes in drinking behavior, and this relationship is allowed to vary by initial religiosity. 
The use of initial religiosity is necessary given the available data, but it is also useful in that it avoids a possible concern for reverse causation: as drinking behaviors change attendance might also change, so that putting contemporary attendance on the right-hand side would produce potentially biased estimates. Since an ex-ante measure of religiosity is invariant, and is measured before the policy changes that will be exploited in the regressions, using initial religiosity for all years avoids this problem.

As in an individual fixed-effects regression, the first-differenced regression will remove any unobserved individual-specific effects (note that this includes all fixed characteristics of the individual, including the noninteracted attendance dummies, as well as controls for gender and race). For the baseline specification, state and year dummies are omitted (of course, their meaning in a first-differenced regression is different than in a levels regression) but regressions including these controls will be considered. Even more strongly, regressions including state-by-year dummies will be considered; this will allow trends in drinking to vary across place and time.

A similar specification will be pursued using data from MLDA laws

$$
\Delta \text { had6 }_{\text {isy }}=\text { rattend }_{i} * \text { ovverage }_{i s y}+\beta \Delta X_{\text {isy }}+\Delta \varepsilon_{i s y},
$$

where variables are defined as before except that overage is a dummy for whether individual $i$ is old enough to legally purchase alcohol, and Doverage is the difference between this dummy for the year in question and in the previous interview year. Once again, noninteracted controls for attend are subsumed by first differencing. As discussed in section 3, the considerable variation in MLDA laws over this period allow for variation across ages, states, and years to contribute to the identification. ${ }^{35}$ State-by-year dummies can also be added to this specification.

The blue laws regression results are reported in Table 5. Standard errors are robust and clustered by state. Column 1 reports estimates including only individuals who reported high ex ante attendance. The estimates show that the repeal of blue laws is associated with a 9 percentage point increase in the

\footnotetext{
${ }^{35}$ About 3,000 observations in the NLSY regressions are from underage respondents, including about 40 percent of 19 year olds and 36 percent of 20 year olds. There are also about 130 respondents in the sample who temporarily lose their legal drinking age status when either changes in MLDAs were not grandfathered or when they move from a low-MLDA state to a high-MLDA state.
} 
likelihood of being a heavy drinker, a reasonably large effect. The next column adds in low and non attendees; the effect of blue laws' repeal on non attendees appears to be large. This result may be driven by non religious individuals responding to newly-available labor and leisure opportunities, a possibility discussed at length by Cohen-Zada and Sander (2009). However, this result may also be driven by the relatively small sample size of non-attendees in repeal states; as shown below, overage drinking results (which use a larger sample and more variation) show negligible effects for non attendees. ${ }^{36}$

However, as discussed in section 2, the key issue here does not concern substitutability among the non-religious or the modestly religious, but whether there is evidence of substitutability among the highly religious. The results clearly show that high attendees increase their heavy drinking after a change in blue laws. The estimates indicate a strong willingness among initially religious individuals to substitute into drinking. Even the regression with state-by-year dummies shown in column 4-a very strong specification—provides evidence of increased heavy drinking among those who were initially the most religious.

The last column tests whether the results so far are truly picking up an increase in drinking among the most religious. It could be (for instance) that some women are highly religious and some women respond strongly to the laws; the regressions in the first three columns constrain all women to have the same response and thus the strong result for high religiosity could simply be driven by changes among women. The last column investigates this story by considering new interactions for the baseline regression. The regressions interact a change in the repeal of blue laws with a dummy for a college education, a dummy for gender, and a dummy for marital status. These new interactions do not erase the effect for highly religious; in fact the estimated effect is stronger than before. The new interaction terms are all smaller than the coefficients of interest. Further, only the married term is significant; this may reflect that, relative to unmarried individuals, married people respond to new labor and leisure opportunities with relatively less heavy drinking, all else equal. But clearly Table 5 suggests that highly

\footnotetext{
${ }^{36}$ The non-attendee result here is also sensitive the sample used and in particular a handful of non-attendees in Texas with extremely large weight values. Removing these individuals yields a smaller and insignificant coefficient on non-attendees, but given the ad-hoc nature of such a result it is not included in the table.
} 
religious individuals are marginal individuals when it comes to incentives to drink, and it does not appear that this effect is driven by some socioeconomic characteristic associated with religiosity.

Table 6 examines whether these results are also found using MLDAs. The first column indicates that heavy drinking among the initially religious increases as individuals reach their MLDA, although the result is somewhat imprecise. The next column adds low and non attendees, the estimates show that highly religious individuals drink more when they reach their MLDA and in this case the statistical precision is greater due to a decrease in the standard error. The 2.4 percentage point increase in column 2 is a little under a 10 percent effect, a number similar and slightly smaller in magnitude than the effects of MLDA laws found in Carpenter and Dobkin (2009). The next two columns, columns 3 and 4, show that this finding is preserved with the addition of state dummies and year dummies, and even (in column 4) with the addition of state-by-year dummies.

The final column in Table 6 once again tests the robustness of this result by adding in additional interaction terms. As with blue laws, the interactions terms actually strengthen the main result; now highly religious individuals have a 4.5 percentage point increase in heavy drinking upon reaching the legal drinking age. The other interacted coefficients are qualitatively similar to those in the blue laws regressions; with only the married interaction being negative. This suggests that, relative to unmarried individuals, married individuals see a relative decline in heavy drinking upon reaching the age of 21. But as before these results suggest that that initially highly religious individuals increase their heavy drinking upon reaching the legal drinking age, and that this increase is economically large and robust.

To summarize, the results of this section present a battery of tests for whether highly religious adherents are willing to substitute between religious and secular consumption; the model in section 2 identifies this as the key metric for documenting a direct effect of religious proscription. The tests here measure "highly religious" using initial religious attendance and denominational affiliation, measure substitution by looking at changes in religious attendance, religious spending, and heavy drinking, and use three sources of variation in incentives: blue laws, casino openings, and MLDAs. Thus the behaviors, price changes, measures of religiosity, datasets, specifications, time periods, populations, and sources of 
variation are different across these tests. In one setting-examining the response of religious attendance to casinos opening in a person's state of residence - there is no evidence of substitutability. In every other instance, the results suggest that highly religious individuals do substitute between religious and secular consumption when incentives change, and that this substitution behavior is robust to various tests and is economically large. The responsiveness of the highly-religious to secular incentives indicates that religious organizations can have strong effects on member behavior through religious proscriptions and other rules that raise the cost of secular activities.

\section{Conclusions}

This paper proposes a general methodology for investigating the importance of religious proscriptions and rules for altering member behavior. The methodology is based on the canonical model of religion and suggests that the impact of proscriptions on behavior will be driven by the willingness of highly religious individuals to substitute between religious and secular consumption. The paper then tests for substitutability in a variety of settings. The results highlight the difference between average participation and marginal participation. Counterintuitively—but crucially—-the model shows that those with extremely high participation may also be highly marginal; this is repeatedly confirmed in the data.

The method developed here requires suitable variation in incentives to undertake secular consumption; an instrument for religion is not required. This method could be applied to any situation where (a) behavior may be potentially related to some aspect of religious proscription or instruction and (b) there is suitable variation in secular incentives to test for substitutability between religious and secular consumption. Examples might include unilateral divorce laws, access to broadband-internet pornography, restrictions on abortion or birth control, and "sin taxes” on cigarettes or other merchandise.

Furthermore, while the model is focused on strict groups, they need not be strict religious groups. The empirical test developed above could also test for causal differences among those adhering to strict secular groups emphasizing costly behaviors that differentiate members from nonmebmers. Examples might include fraternities, sororities, other social clubs, criminal gangs, or terrorist organizations. 
One caveat of the test here is that it is subject to type II error: even lacking evidence that the religious respond to incentives for secular consumption, one might argue that a causal relationship could still exist. The strong empirical results documented above lessen this concern, at least for the contexts considered here. But while the test proposed here is valuable in that it can provide evidence that religious proscriptions matter, the reduced-form nature of the test does not allow a comparison of the relative value of causation versus correlation or non-substitution based channels for causation. However, the economically significant results above suggest that the substitution effect for the religious can be quite strong, suggesting a large direct role for religious proscription on behavior. 


\section{References}

Altonji, Joseph, Todd Elder, and Christopher Taber (2005) "An Evaluation of Instrumental Variable Strategies for Estimating the Effects of catholic Schooling,” The Journal of Human Resources 40(4): 791-821.

Anderson, Robin (2009) "Tribal Casino Impacts on American Indian Household Well-being," Report of the U.S. Census Bureau, Housing and Household Economic Statistics Division.

Argyle, Michael, and Benjamin Beit-Hallahmi (1975) The Social Psychology of Religion. London: Routledge \& Kegan Paul.

Associated Press, The (1984) “Columbia, S.C., Arrests 5 for Defying Blue Laws,” The New York Times, December 25.

Barron, John, Michael Staten, and Stephanie Wilshusen (2002) "The Impact of Casino Gambling on Personal Bankruptcy Filing Rates,” Contemporary Economic Policy 20(4): 440-455.

Berman, Eli (2000) "Sect, Subsidy and Sacrifice: An Economist's View of Ultra-Orthodox Jews," The Quarterly Journal of Economics 3: 905-953.

Beyerlein, Kraig (2004) "Specifying the Impact of Conservative Protestantism on Educational Attainment," Journal for the Scientific Study of Religion 43(4): 505-518.

Bibby, Reginald (1978) "Why Conservative Churches Really are Growing: Kelly Revisted," Journal for the Scientific Study of Religion 17(2): 129-137.

Carpenter, Christopher, and Carlos Dobkin (2009) "The Effect of Alcohol Consumption on Mortality: Regression Discontinuity Evidence from the Minimum Drinking Age” American Economic Journal: Applied Economics 1(1): 164-182.

Cochran, John, and Leonard Beeghley (1991) "The Influence of Religion on Attitudes toward Nonmarital Sexuality: A Preliminary Assessment of Reference Group Theory,” Journal for the Scientific Study of Religion 30(1): 45-62.

Cohen-Zada, Danny and William Sander (2009) "Religious Participation versus Shopping: What Makes People Happier?” working paper

Cook, Philip and George Tauchen (1984) "The Effect of Minimum Drinking Age Legislation on Youthful Auto Fatalities, 1970-1977,” The Journal of Legal Studies 13(1): 169-190.

Dew, Rachel, Stephanie Daniel, Tonya Armstrong, David Goldston, Mary Triplett, and Harold Koenig (2008) "Religion/Spirituality and Adolescent Psychiatric Symptoms," Child Psychiatry and Human Development 39(4): 381-398

Diaz, Joseph (2000) "Religion and Gambling in Sin-City: A Statistical Analysis of the Relationship Between Religion and Gambling Patterns in Las Vegas Residents,” The Social Science Journal 37(3): 453-458.

Du Mouchel, William, Allan Williams, and Paul Zador (1987) "Raising the Alcohol Purchase Age: Its Effects on Fatal Motor Vehicle Crashes in the Twenty-Six States,” Journal of Legal Studies 16(January), 249-266.

Dynes, Russell (1955) "Church-Sect Typology and Socio-Economic Status,” American Sociological Review 20(5): 555-560.

Evans, William and Julie Topoleski (2002) “The Social and Economic Impact of Native American Casinos,” NBER working paper 9198

Ferguson, Kristin, Qiaobing Wu, Donna Spruijt-Metz, and Grace Dyrness (2007) "Outcomes Evaluation in FaithBased Social Services: Are We Evaluating Faith Accurately?” Research on Social Work Practice 17(2): 264-276.

Finke, Roger and Rodney Stark (2006) The Churching of America: Winners and Losers in Our Religious Economy. New Brunswick: Rutgers University Press.

Gerber, Gruber, and Hungerman (2010) "Does Church Attendance Cause People to Vote? Using Blue Laws' Repeal to Estimate the Effect of Religiosity on Voter Turnout," working paper.

Glenmary Research Center (1974) "Churches and Church Membership in the United States, 1971" Glenmary Research Center, Cincinnati, Ohio.

Goos, M. (2005) “The Impact of Shop Closing Hours on Labor and Product Markets,” Working paper.

Grasmick, Harold, Karyl Kinsey, and John Cochran (1991) "Denomination, Religiosity, and Compliance with the Law: A Study of Adults," Journal for the Scientific Study of Religion 30(1): 99-107.

Grinols, Earl and David Mustard (2006) "Casinos, Crime and Community Costs," Review of Economics and Statistics 88(1): 28-45. 
Grossman, Michael, Frank Chaloupka, Henry Saffer, and Adit Laixuthai (1994) "Effects of Alcohol Price Policy on youth: A Summary of Economic Research,” Journal of Research on Adolescence 4(2): 247-364.

Gruber and Hungerman (2008) "The Church vs. the Mall: What Happens when Religion Faces Increased Secular Competition?” Quarterly Journal of Economics 123: 831-862.

Harrison, Michael, and Bernard Lazerwitz (1982) “Do Denominations Matter?” The American Journal of Sociology 88(2): 356-377.

Hammond, Judith, Bettie Cole, and Scott Beck (1993) "Religious Heritage and Teenage Marriage," Review of Religious Research 35(2): 117-133.

Hoffman, John (2000) "Religion and Problem Gambling in the U.S.” Review of Religious Research 41(4): 488-509.

Hoge, Dean (1979) "A Test of Theories of Denominational Growth and Decline," in Hoge and Roozen (eds.) Understanding Church Growth and Decline. New York: Pilgrim Press.

Hoge, Dean, and Fenggang Yang (1994) "Determinants of Religious Giving in American Denominations: Data from Two Nationwide Surveys," Review of Religious Research 36(2): 123-148.

Hungerman, Daniel M (2010) "Rethinking the Study of Religious Markets," in Rachel McCleary (ed.) Handbook of the Economics of Religion: Oxford University Press.

Hungerman, Daniel M (2008) "Race and Charitable Church Activity,” Economic Inquiry 46(3): 380-400.

Iannaccone, Laurence (1988) "A Formal Model of Church and Sect," The American Journal of Sociology 94 supplement: S241-S268.

Iannaccone, Laurence (1992) "Sacrifice and Stigma: Reducing Free-riding in Cults, Communes, and Other Collectives," Journal of Political Economy, 100(2): 271-291.

Iannaccone, Laurence (1994) "Why Strict Churches Are Strong," American Journal of Sociology 99(5): 1180-1211.

Iannaccone, Laurence (1996) "Strictness and Strength Revisited: Reply to Marwell," American Journal of Sociology, 101 (4): 1103-1108.

Iannaccone, Laurence. (1998) "Introduction to the Economics of Religion," Journal of Economic Literature, 36(3): 1465-1495.

Johnson, Byron, Ralph Tompkins, and Derek Webb (2002) "Objective Hope: Assessing the Effectiveness of FaithBased Organizations: A Review of the Literature,” report for the Center for Research on Religion and Urban Civil Society

Johnson, Byron (2008) "Not By Government Alone: Rethinking Prisoner Reentry,” in: Joshi, Hawkins, and Novey (eds) Innovations in Effective Compassion, Report prepared for the U.S. Department of Health and Human Services.

King, W. (1976) “Selling on Sunday Rising Despite Confusing Laws,” The New York Times, May 22, pg 1.

Laband, D. and Heinbuch, D. (1987) Blue Laws. Lexington Books: Lexington, Massachusetts.

Lam, Desmond (2006) “The Influence of Religiosity on Gambling Participation,” Journal of Gambling Studies 22: 305-320.

Lazear, Edward (2000) “Economic Imperialism,” Quarterly Journal of Economics 115(1): 99-146.

Levine, Saul (1984) "Radical Departures,” Psychology Today 18: 20-27.

Lillard Dean, and Joseph Price (2007) "The Impact of Religion on Youth in Disadvantaged Families," working paper.

Makowsky, Michael, (forthcoming a) "Emergent Extremism in a Multi-Agent Model of Religious Clubs," forthcoming in Economic Inquiry

Makowksy, Michael, (forthcoming b) "Religion, clubs, and Emergent Social Divides," forthcoming in The Journal of Economic Behavior \& Organization

Makowsky, Michael (2010) “A Theory of Liberal Churches,” working paper.

Marks, Loren (2005) "Religion and Bio-Psycho-Social Health: A Review and Conceptual Model," Journal of Religion and Health 44(2): 173-186.

McBride, Michael, (2007) "Why Churches Need Free-riders: religious Capital Formation and Religious Group Survival” working paper.

McGee, K. (1991) “North Dakota Sends Blue Laws Packing,” USA Today, February 11.

National Gambling Impact Study Commission. National Gambling Impact Study Commission Final Report. Washington: GPO, June 1999

New York Times, The (1970) “'Day of Rest Act’ Repealed in Utah,” The New York Times, May 17.

Office of the President of the Lutheran Church Missouri Synod (1999) "Promised Gain Comes with Great Pain," A Statement from the Office of the President.

Olson, Paul (2008) "Any Given Sunday: Weekly Church Attendance in a Midwestern City," Journal for the Scientific Study of Religion 47(3): 443-461. 
O’Malley, Patrick, and Alexander Wagenaar (1991) "Effects of Minimum Drinking Age Laws on Alcohol Use, Related Behaviors and Traffic Crash Involvement among American Youth: 1976-1987,” Journal of Studies on Alcohol 52(5): 478-491.

Price, J. and Yandle, B. (1987) "Labor Markets and Sunday Closing Laws,” Journal of Labor Research 4, 407-414.

Regnerus, Mark (2003) "Religion and Positive Adolescent Outcomes: A Review of Research and Theory,” Review of Religious Research 44(4): 394-413,

Reinhold, R. (1985) “Social Legislation Advances in Texas,” The New York Times, June 9, pg 27.

Rew, Lynn and Joel Wong (2006) "A Systematic Review of Associations among Religiosity/Spirituality and Adolescent Health Attitudes and Behaviors," Journal of Adolescent Health 38: 433-442.

Roof, Wade, and William McKinney (1987) American Mainline Religion: Its Changing Shape and Future. New Brunswick: Rutgers University Press.

Rooney, James, and Sanford Schwartz (1977) "The Effect of Minimum Drinking Age Laws upon Adolescent Alcohol use and Problems,” Contemporary Drug Problems, 6: 569-583

Southern Baptist Convention (1996) "Resolution Supporting a National Commission on the Effects of Gambling," A Resolution of the Southern Baptist Convention, June.

Smart, Reginald and Michael Goodstadt (1977) "Effect of Reducing the Legal Alcohol-Purchasing Age on Drinking and Drinking Problems. A Review of Empirical Studies," Journal of Studies on Alcohol 38(7): 1313-1323.

Theuman, J. (2005) "Validity, Construction, and Effect of 'Sunday Closing' or 'Blue' Laws-Modern Status," American Law Reports, ALR4th, 246-332.

United Methodist Church (2004) The Book of Discipline of the United Methodist Church. The United Methodist Publishing House.

Wagenaar, Alexander, and Traci Toomey (2002) "Effects of Minimum Drinking Age Laws: Review and Analyses of the Literature from 1960 to 2000,” Journal of Studies on Alcohol, supplement no. 14: 206-225.

Wallace, John, Valerie Myers, and Esohe Osai (2004) "Faith Matters," A Report Prepared for the Annie E. Casey Foundation

Wechsler, Henry, Jae Lee, Toben Nelson, and Meichun Kuo (2002) “Underage College Students' Drinking Behavior, Access to Alcohol, and the Influence of Deterrence Policies,” Journal of American College Health 50(5): 223-236

Wenz, Michael (2008) "Matching Estimation, Casino Gambling and the Quality of Life,” The Annals of Regional Science 42(1): 235-249

Williams, Allan, Robert Rich, Paul Zador, and Leon Robertson (1975) "The Legal Minimum Drinking Age and Fatal Motor Vehicle Crashes,” Journal of Legal Studies 4(1): 219-239.

Wilson, Bill (1955) Alcoholics Anonymous: The Story of How Many Thousands of Men and Women Have Recovered from Alcoholism. New York: Alcoholics Anonymous World Services, Inc.

Wong, Joel, Lynn Rew, and Kristina Slaikeu (2006) "A Systematic Review of Recent Research on Adolescent Religiosity/Spirituality and Mental Health,” Issues in Mental Health Nursing 27: 161-183. 


\section{Appendix}

Part 1-Deriving Expression (6) from (5)

First, note that the problem solved by individuals in the Nash Equilibrium here is:

$$
\max _{R, S} U(S, R, Q)+\lambda\left(I-\pi_{s} S-\pi_{r} R\right)
$$

Next, totally differentiating (4) yields

$$
\frac{d Q^{e}}{d \pi_{j}}=\left(\frac{\partial F}{\partial \bar{R}} \frac{\partial R}{\partial \pi_{j}}\right) /\left(1-\frac{\partial F}{\partial \bar{R}} \frac{\partial R}{\partial Q}\right)
$$

Plugging (A2) into (5), noting that $\frac{d \log \left(U^{e}\right)}{d \log \left(\pi_{j}\right)}=\frac{d U^{e}}{d \pi_{j}} \frac{\pi_{j}}{U^{e}}$, using Roy’s Identity, and some algebra show:

$$
\frac{d \log \left(U^{e}\right)}{d \log \left(\pi_{j}\right)}=\left(-k_{j}+k_{q} \frac{\varepsilon_{F r} \varepsilon_{r \pi_{j}}}{1-\varepsilon_{F r} \varepsilon_{r q}}\right) \varepsilon_{V I}
$$

where again $\varepsilon_{a b}$ is the elasticity of $a$ with respect to $b, k_{j}$ denotes the expenditure share of commodity $j$, and $k_{q}=\left(Q \frac{\partial V}{\partial Q}\right) /\left(I \frac{\partial V}{\partial I}\right)$. By assumption, the term $\varepsilon_{F r}$ will be positive and by stability $1>\frac{\partial F}{\partial \bar{R}} \frac{\partial R}{\partial Q}=\frac{\partial F}{\partial \bar{R}} \frac{\bar{R}}{F} \frac{\partial R}{\partial Q} \frac{Q}{R}=\varepsilon_{F r} \varepsilon_{r q}$, where the first equality holds given symmetry and since $F=Q$. Thus the expressions in (5) will be positive if the term in parentheses is positive or equivalently if $\left(k_{q} / k_{j}\right) \varepsilon_{r \pi_{j}}>\left(1-\varepsilon_{F r} \varepsilon_{r q}\right) / \varepsilon_{F r}$. This inequality matches (6) except for $k_{q} / k_{j}$.

The expression $k_{q} / k_{j}$ can be written for $j=s$ as $\left(Q \frac{\partial V}{\partial Q}\right) /\left(S \pi_{s} \frac{\partial V}{\partial I}\right)$. From the first-order condition for (A1) we have $\frac{\partial U}{\partial S}=\lambda \pi_{s}=\frac{\partial V}{\partial I} \pi_{s}$, where the second equality follows from the Envelope Theorem. Letting $\frac{\partial V}{\partial I}=\frac{\partial U}{\partial S} \frac{1}{\pi_{s}}$, 


$$
\frac{k_{q}}{k_{j}}=\left(Q \frac{\partial V}{\partial Q}\right) /\left(S \frac{\partial U}{\partial S}\right)
$$

Plugging this in for $k_{q} / k_{j}$ in equilibrium and noting that $\frac{\partial V}{\partial Q}=U_{Q}^{e}$ yields expression (6).

\section{Part 2-Heterogeneous Preferences}

Heterogeneous preferences affect the model by introducing different levels of religiosity in the religious average term $\bar{R}$, which then affects the derivative of group quality used in (5). However, since the derivative of an average is the same as the average of the component derivatives, this heterogeneity has little impact on the intuition and mainly necessitates notational changes.

Consider a situation where there are two types of atomistic individuals in the club, types "a” and "b”. Let the fraction of type-a individuals be $\theta$ and consider a Nash Equilibrium that is symmetric within types. $^{37}$

The key impact heterogeneity in types has on equation (5) is through the term $\frac{d Q^{e}}{d \pi_{s}}$. With heterogeneity in types, expression (4) becomes:

$$
Q^{e}=F\left[\theta R_{a}\left(I, \pi_{s}, \pi_{r}, Q^{e}\right)+(1-\theta) R_{b}\left(I, \pi_{s}, \pi_{r}, Q^{e}\right), N\right]=F\left[\bar{R}\left(I, \pi_{s}, \pi_{r}, Q^{e}\right), N\right] .
$$

Here $R_{j}$ denotes the equilibrium choice of $R$ for a type $j$ individual. Totally differentiating (A4) gives:

$$
\frac{d Q_{i}^{e}}{d \pi_{s}}=\left(\frac{\partial F}{\partial Q} \frac{\partial \bar{R}}{\partial \pi_{s}}\right) /\left(1-\frac{\partial F}{\partial \bar{R}} \frac{\partial \bar{R}}{\partial Q}\right)
$$

\footnotetext{
${ }^{37}$ The case of non-atomistic members is more cumbersome because different members have different perceptions of the equilibrium $Q$, which has no meaningful impact on the intuition and even for small groups is likely unimportant. Recalling that the total number of individuals in the group is $N+1$, a non-atomistic type-a individual's perception of quality is $Q_{a}^{e}=F\left[\left(\hat{\theta} R_{a}+(1-\hat{\theta}) R_{b}\right), N\right]$ where $R_{j}$ is the equilibrium $R$ for a type $j$ individual and $\hat{\theta}=((N+1) \theta-1) / N$ shows for a type-a individual the fraction of the group excluding himself that is also type a. A type-b individual views the fraction of those in the group other than herself who are type a as $\tilde{\theta}=\theta(N+1) / N$. The difference between $\hat{\theta}$ and $\theta$ is $(1-\theta) / N$ and the difference between $\tilde{\theta}$ and $\theta$ is $\theta / N$; both of which will typically be negligible even for small religious groups. A non-atomistic analysis approximating $\tilde{\theta}$ and $\hat{\theta}$ with $\theta$ is similar to the derivation of (A6) given here.
} 
where $\frac{\partial \bar{R}}{\partial \pi_{s}}=\theta \frac{\partial R_{a}}{\partial \pi_{s}}+(1-\theta) \frac{\partial R_{b}}{\partial \pi_{s}}$ and $\frac{\partial \bar{R}}{\partial Q}=\theta \frac{\partial R_{a}}{\partial Q}+(1-\theta) \frac{\partial R_{b}}{\partial Q}$.

Using expression (A5) yields a slightly altered version of (A3):

$$
\frac{d \log \left(U^{e}\right)}{d \log \left(\pi_{j}\right)}=\left(-k_{j}+k_{q} \frac{\bar{\varepsilon}_{F r} \bar{\varepsilon}_{r \pi_{j}}}{1-\bar{\varepsilon}_{F r} \bar{\varepsilon}_{r q}}\right) \varepsilon_{V I},
$$

where $\bar{\varepsilon}_{F r} \bar{\varepsilon}_{r \pi_{j}}=\frac{\partial F}{\partial \bar{R}} \frac{\bar{R}}{F} \frac{\partial \bar{R}}{\partial \pi_{j}} \frac{\pi_{j}}{\bar{R}}$ and $\bar{\varepsilon}_{F r} \bar{\varepsilon}_{r q}=\frac{\partial F}{\partial \bar{R}} \frac{\bar{R}}{F} \frac{\partial \bar{R}}{\partial Q} \frac{Q}{\bar{R}}$. The rest of the derivation of (6) proceeds as before.

\section{Part 3-Proposition}

For part (a), suppose instead that high types are in the low-proscription club. In this case the utility of low-type individual $i$ is $U^{i l}\left(S^{i}, R^{i}, Q^{l}\right)$, where $Q^{l}=F\left(\bar{R}^{l}, 1\right)$ and since agents are atomistic this quality is the same for all agents in the low-proscription club. By assumption, low types have lower levels of $R$ in equilibrium and both clubs are equally sized, thus $Q^{l}<Q^{h}$, where $Q^{h}$ is quality in the high proscription club. Since low types do not want to switch to the low-proscription club, it must be the case that $V^{i l}\left(S\left(\bar{\pi}_{s}, Q^{l}\right), R\left(\bar{\pi}_{s}, Q^{l}\right), Q^{l}\right)>V^{i l}\left(S\left(\underline{\pi}_{s}, Q^{h}\right), R\left(\underline{\pi}_{s}, Q^{h}\right), Q^{h}\right)$, where $V^{i l}$ is the individuals' indirect utility function, and $R\left(\pi_{s}, Q\right)$ and $S\left(\pi_{s}, Q\right)$ are the individuals' optimal choices of $R$ and $S$ given $\pi_{s}$ and $Q . \quad$ Next, $V^{i l}\left(S\left(\underline{\pi}_{s}, Q^{h}\right), R\left(\underline{\pi}_{s}, Q^{h}\right), Q^{h}\right)>V^{i l}\left(S\left(\underline{\pi}_{s}, Q^{l}\right), R\left(\underline{\pi}_{s}, Q^{l}\right), Q^{h}\right)$; if this did not hold then $S\left(\underline{\pi}_{s}, Q^{h}\right)$ and $R\left(\underline{\pi}_{s}, Q^{h}\right)$ would not be optimal choices. By assumption utility is increasing in quality, all else equal, so that $V^{i l}\left(S\left(\underline{\pi}_{s}, Q^{l}\right), R\left(\underline{\pi}_{s}, Q^{l}\right), Q^{h}\right)>V^{i l}\left(S\left(\underline{\pi}_{s}, Q^{l}\right), R\left(\underline{\pi}_{s}, Q^{l}\right), Q^{l}\right)$. Combining these three inequalities, $V^{i l}\left(S\left(\bar{\pi}_{s}, Q^{l}\right), R\left(\bar{\pi}_{s}, Q^{l}\right), Q^{l}\right)>V^{i l}\left(S\left(\underline{\pi}_{s}, Q^{l}\right), R\left(\underline{\pi}_{s}, Q^{l}\right), Q^{l}\right)$. But this is not possible, since-holding $Q$ constant—indirect utility cannot rise as prices rise; the optimal choices of $R$ and $S$ when the secular price is high can still be obtained with the secular price is lowered. Thus we have a contradiction. 
Part (b) follows from the derivation of (6) from (5) described at the start of the appendix. In particular, multiplying equation (A3) by $V=U^{h}$ shows that $\frac{d U^{h}}{d \bar{\pi}_{s}}=\frac{1}{\bar{\pi}_{s}}\left(-S^{h} U_{S}^{h}+Q^{h} U_{Q}^{h} \varepsilon_{r \pi_{s}} \frac{\varepsilon_{F r}}{1-\varepsilon_{F r} \varepsilon_{r q}}\right)$ where $\frac{\varepsilon_{F r}}{1-\varepsilon_{F r} \varepsilon_{r q}}>0$

For part (c), derivation of equation (1) yields $\left.\pi_{r} \frac{\partial R}{\partial \pi_{s}}\right|_{\substack{R=R^{h} \\ S=S^{h} \\ Q=Q^{h}}}+\left.\pi_{s} \frac{\partial S}{\partial \pi_{s}}\right|_{\substack{R=R^{h} \\ S=S^{h} \\ Q=Q^{h}}}=-S^{h}$, where $S^{h}$ represents the equilibrium choice of $S$ for high types (and similarly for $R^{h}$ and $Q^{h}$ ), or equivalently, $\left.k_{r}^{h} \varepsilon_{r \pi_{s}}\right|_{\substack{R=R^{h} \\ S=S^{h} \\ Q=Q^{h}}}+\left.k_{s}^{h} \varepsilon_{s \pi_{s}}\right|_{\substack{R=R^{h} \\ S=S^{h} \\ Q=Q^{h}}}=-\left.k_{s}^{h}\right|_{\substack{R=R^{h} \\ S=S^{h} \\ Q=Q^{h}}}$ where $k_{j}^{h}$ is high-types' expenditure share of commodity $j$. (The equal sign is trivially ensured by the assumption that utility is increasing in all goods.) 


\section{Figure 1: Counties with a Casino}

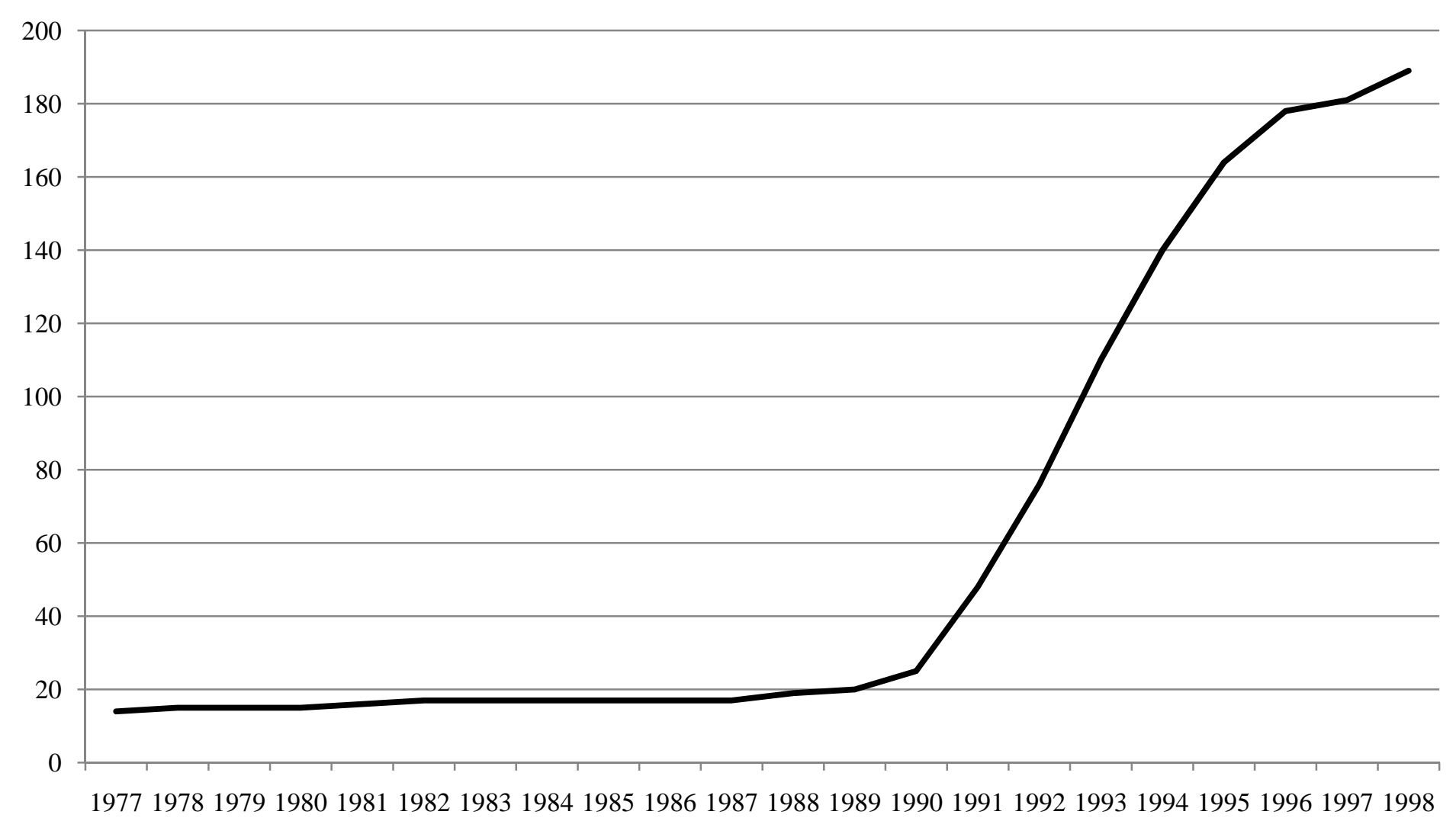

The figure shows the number of counties with a casino each year from 1977 to 1998 . Casinos here refer to Class III casinos (see text). 


\section{Table 1: Datasets and Selected Descriptive Statistics}

Panel A: Church Spending Data for Blue Laws
\begin{tabular}{|l|c|c|}
\hline Denomination & $\begin{array}{c}\text { Years Data } \\
\text { Available }\end{array}$ & Blue-Law States Available \\
\hline Southern Baptist Convention & $1968-2000$ & $\begin{array}{c}\text { AZ, CA, CO, FL, IA, IN, KS, NM, NV, OH, SC, } \\
\text { TN, TX, VA, WY }\end{array}$ \\
\hline Lutheran Church Missouri Synod & $1951-1991$ & CA, FL, IA, IN, KS, MN, ND, OH, SD, TX \\
\hline United Methodist Church & $1962-2000$ & CA, CO, FL, IA, IN, KS, MN, OH, OR, PA, SC, TN, \\
\hline United Church of Christ & $1950-2000$ & AZ, CA, CO, FL, IA, IN, MN, OH, PA, TX, VT \\
\hline
\end{tabular}

There are 16 states that repealed blue laws: FL (blue law repealed in 1969), IA ( 1955), IN (1977), KS (1965), MN (1985), ND (1991), OH (1973), PA (1978), SC (1985), SD (1977), TN (1981), TX (1985), UT (1973), VA (1975), VT (1982), WA (1966). There are 8 states that never had blue laws: AZ, CA, CO, ID, NV, NM, OR, and WY. Of these, the only states not covered by any denomination any year are Utah and Idaho. For some denominations, data on a state are only available for a subset of years.

Panel B: Church Spending Data for Casino Regressions

\begin{tabular}{|l|c|c|}
\hline Denomination & $\begin{array}{c}\text { Years Data } \\
\text { Available }\end{array}$ & $\begin{array}{c}\text { States Available } \\
\text { Southern Baptist Convention }\end{array}$ \\
\hline Lutheran Church Missouri Synod & $1968-1998$ & $\begin{array}{c}\text { AL, AR, AZ, CA, CO, FL, GA, IA, IL, IN, KS, KY, } \\
\text { LA, MI, MO, MS, NC, NM, NV, NY, OH, OK, SC, } \\
\text { TN, TX, VA, WV, WY }\end{array}$ \\
\hline United Methodist Church & $1951-1991$ & $\begin{array}{c}\text { CA, FL, IA, IL, IN, KS, MI, MN, MO, MT, ND, } \\
\text { NE, NJ, NY, OH, OK, SD, TX, WI }\end{array}$ \\
\hline United Church of Christ & $1962-1998$ & $\begin{array}{c}\text { AL, AR, CA, CO, FL, GA, IA, IL, IN, KS, KY, LA, } \\
\text { MD, MI, MN, MO, MS, MT, NC, NE, NJ, NY, OH, } \\
\text { OK, OR, PA, SC, TN, TX, VA, WA, WI, WV }\end{array}$ \\
\hline
\end{tabular}

For some denominations, data on a state are only available for a subset of years. There are 45 states included by at least one denomination; the 5 states not included are Alaska, Delaware, Hawaii, Idaho, and Utah.

\section{Panel C: Select GSS Means}

\begin{tabular}{|l|c|}
\hline Variable & Mean \\
\hline Dummy for at least weekly worship attendance & 0.29 \\
\hline Dummy for worship attendance less than weekly but more than never & 0.57 \\
\hline Number of counties in respondent's state with a casino & 0.97 \\
\hline Dummy for whether blue laws have been repealed in respondent's state (1 = repealed) & 0.81 \\
\hline
\end{tabular}

Data are from 1973-1998 waves of the General Social Survey. All variables except for the blue-laws dummy are based on a sample of 34,760 respondents. The blue-laws dummy is based on the sample of respondents in the 16 usable blue laws states listed under panel A; the sample size for this variable is 11,720.

\section{Panel D: Select NLSY Means}

\begin{tabular}{|l|c|}
\hline Variable & Mean \\
\hline Had 6 or more alcoholic drinks on one occasion in the past month & 0.34 \\
\hline Attended religious services at least once a week in past year (in 1979) & 0.33 \\
\hline Attended religious services less than weekly but more than never in the past year (in 1979) & 0.48 \\
\hline
\end{tabular}

Data are from the NLSY 79 with a total of 56,969 observations. The sample used for these means matches the sample in column 1 of Table 7 . The mean of the drinking variable for weekly attendees is 0.288 ; for moderate attendees it is 0.362 and for nonattendees it is 0.396 . 


\section{Table 2:}

\section{Blue Laws and Spending}

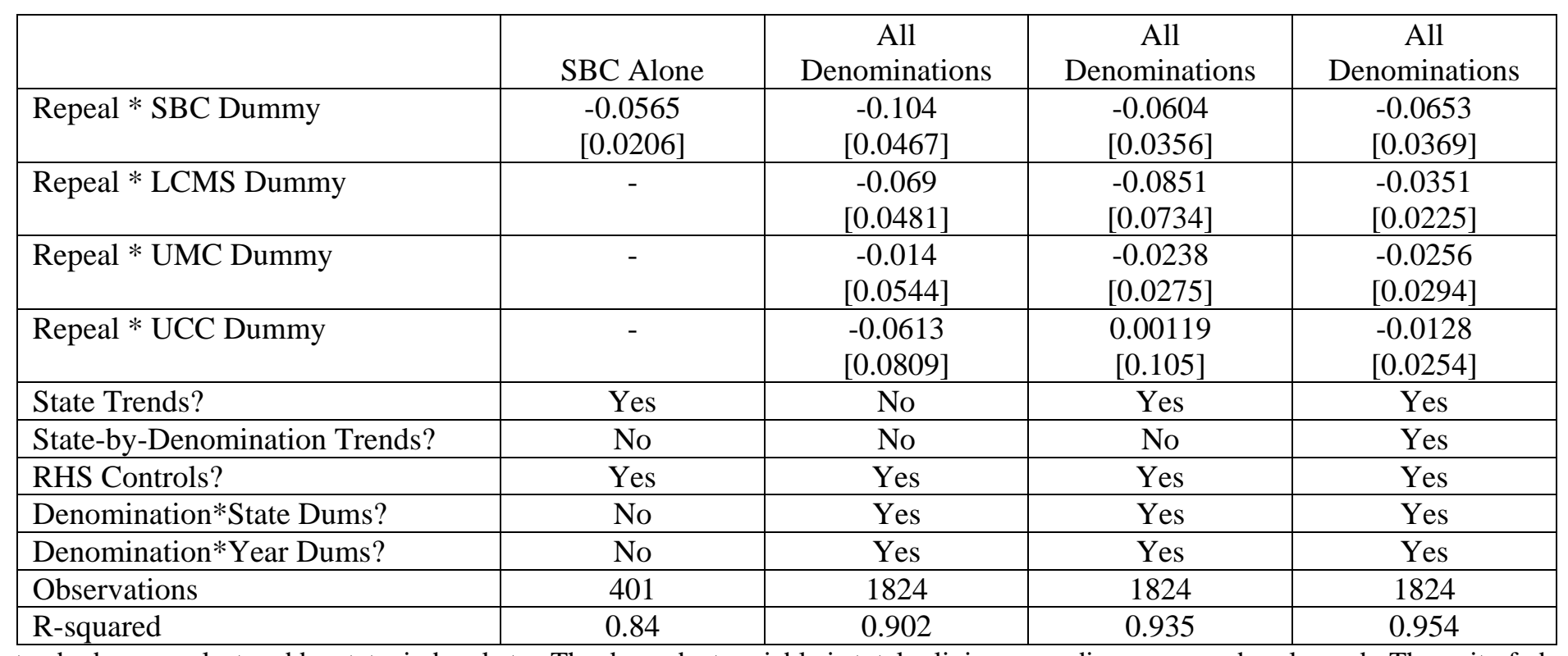

Robust standard errors, clustered by state, in brackets. The dependent variable is total religious spending, per member, logged. The unit of observation is all churches in a given denomination, in a given state and year. The repeal dummy equals 1 in a given state and year where blue laws have been repealed. The sample includes data from any available state that repealed its blue laws (or never had blue laws), see panel A of Table 1 for more information. The regressions omit state/year observations the year that a state repeals its law. The denominations used are the Southern Baptist Convention (SBC), Lutheran Church Missouri Synod (LCMS), United Methodist Church (UMC), and United Church of Christ (UCC). Column 1 reports results using only SBC churches; this regression includes state dummies, year dummies, and state time trends, but does not interact them with a denomination dummy (since there is only one denomination in this regression). Regressions are weighted by total membership. Right hand side controls include the percent of individuals in a state under age 5 , between 5 and 18, between 45 and 64, and over 65, the percent of individuals in a state black , the percent foreign born, the rate of insured unemployment, and per capita disposable income. All monetary figures are in year 2000 dollars. Mean per-member spending, in levels, is \$383. 
Table 3:

\section{Casinos and Spending}

\begin{tabular}{|c|c|c|c|c|}
\hline & SBC Alone & $\begin{array}{c}\text { All } \\
\text { Denominations }\end{array}$ & $\begin{array}{c}\text { All } \\
\text { Denominations }\end{array}$ & $\begin{array}{c}\text { All } \\
\text { Denominations }\end{array}$ \\
\hline Casinos * SBC Dummy & $\begin{array}{c}-0.0107 \\
{[0.00335]}\end{array}$ & $\begin{array}{c}-0.00739 \\
{[0.00584]}\end{array}$ & $\begin{array}{c}-0.0163 \\
{[0.00473]}\end{array}$ & $\begin{array}{c}-0.0113 \\
{[0.00422]}\end{array}$ \\
\hline Casinos * LCMS Dummy & - & $\begin{array}{c}0.0001 \\
{[0.00929]}\end{array}$ & $\begin{array}{c}0.00529 \\
{[0.00680]}\end{array}$ & $\begin{array}{c}-0.00649 \\
{[0.00359]}\end{array}$ \\
\hline Casinos * UMC Dummy & - & $\begin{array}{c}0.00671 \\
{[0.00603]}\end{array}$ & $\begin{array}{c}0.000147 \\
{[0.00518]} \\
\end{array}$ & $\begin{array}{c}-0.00281 \\
{[0.00401]} \\
\end{array}$ \\
\hline Casinos * UCC Dummy & - & $\begin{array}{c}-0.00527 \\
{[0.00353]}\end{array}$ & $\begin{array}{c}-0.00398 \\
{[0.00490]}\end{array}$ & $\begin{array}{c}0.00268 \\
{[0.00380]}\end{array}$ \\
\hline State Trends? & Yes & No & Yes & Yes \\
\hline State by Denomination Trends? & No & No & No & Yes \\
\hline RHS Controls? & Yes & Yes & Yes & Yes \\
\hline Denomination*State Dums? & No & Yes & Yes & Yes \\
\hline Denomination*Year Dums? & No & Yes & Yes & Yes \\
\hline Observations & 748 & 3657 & 3657 & 3657 \\
\hline R-squared & 0.89 & 0.913 & 0.944 & 0.956 \\
\hline
\end{tabular}

Robust standard errors, clustered by state, in brackets. The dependent variable is total religious spending, per member, logged. The unit of observation is all churches in a given denomination, in a given state and year. The Casinos variable is the number of counties in a given state and year operating a Class III casino. The denominations used are the Southern Baptist Convention (SBC), Lutheran Church Missouri Synod (LCMS), United Methodist Church (UMC), and United Church of Christ (UCC). Column 1 reports results using only SBC churches; this regression includes state dummies, year dummies, and state time trends, but does not interact them with a denomination dummy (since there is only one denomination in this regression). Regressions are weighted by total membership. Right hand side controls include the percent of individuals in a state under age 5 , between 5 and 18 , between 45 and 64, and over 65, the percent of individuals in a state black , the percent foreign born, the rate of insured unemployment, and per capita disposable income. All monetary figures are in year 2000 dollars. Mean per-member spending, in levels, for the full regression sample, is \$367. The mean number of counties with a casino in the sample is 0.6; the maximum number of counties with casinos is 15. 
Table 4: Church Attendance

\section{Panel A: Blue Laws}

\begin{tabular}{|l|c|c|c|c|c|c|}
\hline & \multicolumn{2}{|c|}{ High Attendee } & \multicolumn{2}{c|}{ Low Attendee } & \multicolumn{2}{c|}{ Non Attendee } \\
\hline Repeal Dummy & $\begin{array}{c}-0.0445 \\
{[0.0158]}\end{array}$ & $\begin{array}{c}-0.0714 \\
{[0.0236]}\end{array}$ & $\begin{array}{c}0.0327 \\
{[0.0147]}\end{array}$ & $\begin{array}{c}0.0477 \\
{[0.0192]}\end{array}$ & $\begin{array}{c}0.0118 \\
{[0.0122]}\end{array}$ & $\begin{array}{c}0.0236 \\
{[0.0148]}\end{array}$ \\
\hline State Trends? & No & Yes & No & Yes & No & Yes \\
\hline RHS Controls? & Yes & Yes & Yes & Yes & Yes & Yes \\
\hline Observations & 16143 & 16143 & 16143 & 16143 & 16143 & 16143 \\
\hline R-squared & 0.07 & 0.072 & 0.048 & 0.049 & 0.048 & 0.05 \\
\hline
\end{tabular}

\section{Panel B: Casinos}

\begin{tabular}{|l|c|c|c|c|c|c|}
\hline & \multicolumn{2}{|c|}{ High Attendee } & \multicolumn{2}{c|}{ Low Attendee } & \multicolumn{2}{c|}{ Non Attendee } \\
\hline Casino Counties & $\begin{array}{c}-0.0010 \\
{[0.00135]}\end{array}$ & $\begin{array}{c}0.0015 \\
{[0.0023]}\end{array}$ & $\begin{array}{c}0.00046 \\
{[0.0014]}\end{array}$ & $\begin{array}{c}0.00083 \\
{[0.0029]}\end{array}$ & $\begin{array}{c}0.00053 \\
{[0.001]}\end{array}$ & $\begin{array}{c}-0.0023 \\
{[0.0015]}\end{array}$ \\
\hline State Trends? & No & Yes & No & Yes & No & Yes \\
\hline RHS Controls? & Yes & Yes & Yes & Yes & Yes & Yes \\
\hline Observations & 34760 & 34760 & 34760 & 34760 & 34760 & 34760 \\
\hline R-squared & 0.071 & 0.073 & 0.03 & 0.032 & 0.051 & 0.052 \\
\hline
\end{tabular}

Robust standard errors, clustered by state, in brackets. All regressions are linear probability regressions. The dependent variable for "high attendee" regressions is a dummy that equals 1 if an individual reports attending worship at least once a week. The dependent variable for "low attendee" regressions equals 1 if attendance is greater than never but less than weekly. The dependent variable for the "non-attendee" regressions equals 1 if an individual does not attend worship. All regressions include regressors for respondent's gender, race, educational status, marital status, age, the percent of individuals in a state black, the percent foreign born, the rate of insured unemployment, per capita disposable income, state dummies, and year dummies. All regressions are run on GSS data from 1973 to 1998. The regressions in panel A here are limited to the states listed below panel A of Table 1 . The blue laws regressions omit state/year observations the year that a state repeals its law. The Casino Counties variable in panel B reports the number of counties in a given state and year operating a Class III casino. 
Table 5:

Blue Laws \& Heavy Drinking

\begin{tabular}{|c|c|c|c|c|c|}
\hline & $\begin{array}{l}\text { Only High } \\
\text { Attendees }\end{array}$ & Baseline & $\begin{array}{c}\text { w/State \& Yr } \\
\text { Dummies }\end{array}$ & $\begin{array}{c}\text { w/State-by-Yr } \\
\text { Dummies }\end{array}$ & $\begin{array}{c}\text { Extra } \\
\text { Interactions }\end{array}$ \\
\hline High Attendee $* \Delta$ Repeal & $\begin{array}{c}0.0929 \\
{[0.0548]}\end{array}$ & $\begin{array}{c}0.0876 \\
{[0.0409]}\end{array}$ & $\begin{array}{c}0.0840 \\
{[0.0397]}\end{array}$ & $\begin{array}{c}0.0639 \\
{[0.0402]}\end{array}$ & $\begin{array}{c}0.0777 \\
{[0.0448]}\end{array}$ \\
\hline Low Attendee $* \Delta$ Repeal & - & $\begin{array}{c}0.0216 \\
{[0.0449]}\end{array}$ & $\begin{array}{c}0.0161 \\
{[0.0462]}\end{array}$ & $\begin{array}{l}-0.0017 \\
{[0.0483]}\end{array}$ & $\begin{array}{c}0.011 \\
{[0.0420]}\end{array}$ \\
\hline Non Attendee $* \Delta$ Repeal & - & $\begin{array}{c}0.1506 \\
{[0.0584]}\end{array}$ & $\begin{array}{c}0.1406 \\
{[0.0615]}\end{array}$ & $\begin{array}{c}0.1157 \\
{[0.0583]}\end{array}$ & $\begin{array}{c}0.1440 \\
{[0.0527]}\end{array}$ \\
\hline College $* \Delta$ Repeal & - & - & - & - & $\begin{array}{c}-0.0146 \\
{[0.0271]}\end{array}$ \\
\hline Woman $* \Delta$ Repeal & - & - & - & - & $\begin{array}{c}0.0521 \\
{[0.0330]}\end{array}$ \\
\hline Married $* \Delta$ Repeal & - & - & - & - & $\begin{array}{c}-0.0401 \\
{[0.0183]}\end{array}$ \\
\hline State-by-Year Dummies? & No & No & No & Yes & No \\
\hline First-Differenced Data? & Yes & Yes & Yes & Yes & Yes \\
\hline State Dummies? & No & No & Yes & Yes & No \\
\hline Year Dummies? & No & No & Yes & Yes & No \\
\hline RHS Controls? & Yes & Yes & Yes & Yes & Yes \\
\hline Observations & 9453 & 28103 & 28103 & 28103 & 28103 \\
\hline R-squared & 0.037 & 0.029 & 0.039 & 0.046 & 0.029 \\
\hline
\end{tabular}

Robust standard errors, clustered by state, in brackets. The dependent variable is a dummy for whether a respondent reports having 6 or more drinks in one sitting in the past 30 days (first differenced). The regression sample is from the 1983, 1984, 1985, 1988, 1989, and 1994 waves of the NLSY 79. The regressions include the first differences of a set of individual and state controls, a set of age dummies, a set of dummies for years since last interview, and controls for the percent of individuals in a state black, the percent foreign born, the rate of insured unemployment, per capita disposable income. The first column limits the sample only to those who initially (in 1979) reported high attendance. These regressions are limited to the 24 states below panel A of Table. 
Table 6:

Legal Drinking Age \& Heavy Drinking

\begin{tabular}{|c|c|c|c|c|c|}
\hline & $\begin{array}{l}\text { Only High } \\
\text { Attendees }\end{array}$ & Baseline & $\begin{array}{l}\text { w/State \& Yr } \\
\text { Dummies }\end{array}$ & $\begin{array}{l}\text { w/State-by-Yr } \\
\text { Dummies }\end{array}$ & $\begin{array}{c}\text { Extra } \\
\text { Interactions }\end{array}$ \\
\hline High Attendee $* \Delta$ Overage & $\begin{array}{c}0.0231 \\
{[0.0192]}\end{array}$ & $\begin{array}{c}0.024 \\
{[0.0162]}\end{array}$ & $\begin{array}{c}0.0303 \\
{[0.0165]}\end{array}$ & $\begin{array}{c}0.0282 \\
{[0.0162]}\end{array}$ & $\begin{array}{c}0.0452 \\
{[0.0240]}\end{array}$ \\
\hline Low Attendee $* \Delta$ Overage & - & $\begin{array}{c}0.018 \\
{[0.0200]}\end{array}$ & $\begin{array}{c}0.0206 \\
{[0.0188]}\end{array}$ & $\begin{array}{c}0.0193 \\
{[0.0191]}\end{array}$ & $\begin{array}{c}0.0377 \\
{[0.0221]}\end{array}$ \\
\hline Non Attendee $* \Delta$ Overage & - & $\begin{array}{c}-0.0123 \\
{[0.0334]}\end{array}$ & $\begin{array}{c}-0.0038 \\
{[0.0328]}\end{array}$ & $\begin{array}{l}-0.0023 \\
{[0.0326]}\end{array}$ & $\begin{array}{c}0.0084 \\
{[0.0367]}\end{array}$ \\
\hline College $* \Delta$ Overage & - & - & - & - & $\begin{array}{c}0.0019 \\
{[0.0480]}\end{array}$ \\
\hline Woman $* \Delta$ Overage & - & - & - & - & $\begin{array}{c}-0.024 \\
{[0.0258]}\end{array}$ \\
\hline Married $* \Delta$ Overage & - & - & - & - & $\begin{array}{c}-0.0432 \\
{[0.0224]}\end{array}$ \\
\hline State-by-Year Dummies? & No & No & No & Yes & No \\
\hline First-Differenced Data? & Yes & Yes & Yes & Yes & Yes \\
\hline State Dummies? & No & No & Yes & Yes & No \\
\hline Year Dummies? & No & No & Yes & Yes & No \\
\hline RHS Controls? & Yes & Yes & Yes & Yes & Yes \\
\hline Observations & 18902 & 56969 & 56969 & 56969 & 56969 \\
\hline R-squared & 0.033 & 0.031 & 0.042 & 0.05 & 0.031 \\
\hline
\end{tabular}

Robust standard errors, clustered by state, in brackets. The dependent variable is a dummy for whether a respondent reports having 6 or more drinks in one sitting in the past 30 days (first differenced). The regression sample is from the 1983, 1984, 1985, 1988, 1989, and 1994 waves of the NLSY 79. The regressions include the first differences of a set of individual and state controls, a set of age dummies, a set of dummies for years since the last interview, and controls for the percent of individuals in a state black, the percent foreign born, the rate of insured unemployment, per capita disposable income. The first column limits the sample only to those who initially (in 1979) reported high attendance. 